\title{
Exploring the Effect of Asperity Order on Mechanical Character of Joint Specimen from the Perspective of Damage
}

\author{
Zhouhao Yuan $\mathbb{D},{ }^{1}$ Yicheng Ye, ${ }^{1,2}$ and Binyu Luo $\mathbb{D}^{1}$ \\ ${ }^{1}$ School of Resources and Environmental Engineering, Wuhan University of Science and Technology, Wuhan 430081, China \\ ${ }^{2}$ Industrial Safety Engineering Technology Research Center of Hubei Province, Wuhan 430081, China \\ Correspondence should be addressed to Binyu Luo; binyul@126.com
}

Received 22 May 2021; Accepted 16 July 2021; Published 16 August 2021

Academic Editor: Na Huang

Copyright ( 2021 Zhouhao Yuan et al. This is an open access article distributed under the Creative Commons Attribution License, which permits unrestricted use, distribution, and reproduction in any medium, provided the original work is properly cited.

\begin{abstract}
The joint morphology is multiscale. The effect of each asperity order on the mechanical properties of joints is different. The shear mechanical properties of joint specimens are related to its surface damage characteristics. At present, there are still few studies on the effect of roughness on the shearing mechanical properties of joint from the perspective of damage of each asperity order. In this paper, the standard roughness profile was chosen as initial morphology. The standard roughness profile was decomposed into waviness and unevenness by the method combine the ensemble empirical mode decomposition (EEMD) and the cut-off criterion. Then, the joint specimen which contains waviness and unevenness and the specimen which only contains waviness were prepared by the 3D engraving technology. The 40 sets of joint specimens with different asperity order were subjected to direct shear tests under different normal stresses. Based on the 3D scanning technology and ICP iterative method, the damaged area and the damage volume were calculated. Based on the damage volume data and the acoustic emission (AE) data, the effect of asperity order to the joint mechanical behaviour was studied. The results indicate that (1) under low normal stress, the unevenness plays a control role in the failure mode of the joint specimen. Under low normal stress, the joint surface containing only waviness exhibits slip failure, and the joint surface with unevenness exhibits shear failure. With the increase of the normal stress, the failure mode of the specimen containing only waviness changes from slip failure to shear failure; (2) the unevenness controls the damage degree of the joint specimen. The damaged area, damage volume, AE energy rate, and accumulative AE energy of the joint specimen with unevenness are larger than those of the specimen with only waviness, and this difference increases with the normal stress increase; (3) the difference between the joint specimen with unevenness and specimen with only waviness mainly exists in the prepeak nonlinear stage and the postpeak softening stage. The characteristic parameters of acoustic emission generated in the postpeak softening stage of the joint specimen with unevenness are greater than those of the specimen with only waviness. This phenomenon can be used to explain the stress drop difference at the postpeak softening stage; (4) the AE $b$ value can be used to evaluate the damage of joint specimens. Analysing the damage difference of each asperity order under different normal stresses is of great significance to the analysis of the influence of the morphology of the joint surface on the mechanical properties of the joint.
\end{abstract}

\section{Introduction}

The rock mass contains a large number of weak planes, such as rock joints, bedding planes, and fractures, caused by underground excavations and geothermal energy reservoir production [1-4]. The stability of the rock mass was controlled by the shear strength of these weak planes [5]. The shear strength of the rock joint was influenced by many parameters, such as normal stress, uniaxial stress, surface asperity, and joint match ratio. Among these parameters, the surface asperity is highly crucial [6-8].

The surface asperity is multiscale [9]. According to its geometric characteristic, the surface can be divided into primary asperity (waviness) and secondary asperity (unevenness). Patton [10] found that the effect of waviness and unevenness to the shear behaviour is different at first. In order to further explore their influence on the shear behaviour of the joint specimen, further shear tests were conducted 
on the joint specimen. It is concluded that when the normal stress is low, the unevenness plays a key role in the shear behaviour; on the contrary, the waviness plays a control role in the shear behaviour of the joint specimen[11-15]. However, the research object of the abovementioned research is the joint specimen that contains both waviness and unevenness. In order to understand the influence of the waviness and unevenness on the shear behaviour of the joint specimens, it is necessary to decompose the joint surface into waviness and unevenness for analysis.

There are many ways to decompose the joint surface into waviness and unevenness, such as the Fourier series method [16-18], Gaussian filter method [19], different sampling interval method $[20,21]$, and wavelet analysis method [2226]. The above methods have their own advantage and disadvantage it is still not known which one is the best up to now. Yang et al. $[17,18]$ identify the waviness and the unevenness of the joint surface by visual comparison. Jiang et al. [19] and Hong et al. [27] used the cut-off wavelength to distinguish the waviness and unevenness. Zou et al. [23], Wang et al. [24], Gui et al. [25], and Li et al. [26] proposed a critical cut-off level by the variance of the approximate component and think that, the critical decomposition is achieved when the standard deviation of the approximate component drops significantly. It is also proposed that the unevenness of the joint surface should obey the Gaussian distribution, and its distribution can be checked by the Shapiro-Wilk test method. At the same time, there is no unified criterion for the critical decomposition level of waviness and unevenness. Therefore, further research is needed in the decomposition method and critical decomposition level.

Yang et al. [18] reconstruct the joint surface containing the waviness and unevenness and the surface only containing the waviness by the Fourier series method and found that the waviness plays a control role in the normal displacement during the shear process. Hong et al. [28] divide the joint surface into waviness and unevenness by the Gaussian filtering method and then explore their mechanical contribution to the shear strength of the joint specimen under low normal stress and believed that identifying the degradation of the unevenness is important for evaluating the contribution of the waviness and unevenness to the peak shear strength. Yang et al. [18] proposed that there has a direct relationship between the damaged area caused by shearing and the shear strength under low normal stress. So the damage height of the joint specimen will affect the mechanical behaviour of the joint specimen. However, Yang et al. [18] and Hong et al. [28] analysed the damage of the joint specimen from two-dimensional rather than three-dimensional to capture the asperity damage.

The damaged area and damage volume of the joint surface can only reflect the damage ratio at the end of the shear test, and it is difficult to reflect the damage evolution process during the shearing process $[29,30]$. Acoustic emission technology is widely used to study the damage of joint specimen during shear [31]. Zhou et al. [32] analysed the change rule of acoustic emission signal during the shear process and proposed that the changing law of $\mathrm{AE}$ events and energy rate was greatly affected by the roughness and normal stress. Moradian et al. [33] used acoustic emission technology to analyse the damage evolution during shear and found that joint specimen with more unevenness produced more AE energy. Meng et al. [34] analysed the acoustic emission signals of the joint specimen with different lithologies (granite, marble, cement, and similar materials) under different conditions (normal stress, shear rate) and proposed that the shear damage can be characterized by acoustic emission parameters (cumulative energy and cumulative events). Chen et al. [35] used 3D scan technology to quantify the shear damage volume and monitored the acoustic emission energy during the shear and then established the relationship between joint specimen damage volume and acoustic emission energy.

In summary, the asperity order shows an important effect on the shear behaviour of the joint specimen, which is mainly reflected in the contribution difference of the waviness and unevenness to mechanical characteristics of rock joints. It can be indicated that the damaged area is one of the factors affecting the shear strength of the joint specimen. However, current understanding about the impact of the asperity order on the damage degree of the joint specimen is still insufficient, and further research is needed to quantify the difference in the damage degree caused by the asperity order. Besides, the standard roughness profile was chosen as initial joint morphology, and the standard roughness profile was digitized by the gray-scale image processing method and decomposed into the waviness and unevenness by the method which combines the EEMD and cut-off level criterion. Six standard roughness profiles $\left(6^{\#} \sim 10^{\#}\right.$ standard profile) and their decomposed waviness component were chosen as the engraving path to prepare the joint specimen, and shear tests under different normal stresses were carried out. The acoustic emission system was used to monitor the damage of the joint specimen during shearing. The 3D scanning and ICP iteration method were used to quantify the damaged area and damage volume of the joint specimen; finally, the acoustic emission parameter AE- $b$ value was used to characterize the influence of the asperity order on the damage of the joint specimen.

\section{Test Method}

\subsection{Standard Roughness Profile Decomposition}

2.1.1. The Method for Decomposition Standard Roughness Profile. In this paper, the standard roughness profile (Figure 1(a)) was chosen as the initial morphology and digitized by the gray-scale image processing method [36]. Then, the digitizing data was utilized to reconstruct the standard roughness profile in the origin software (Figure 1(b)). It can be found that the standard roughness profile and the reconstructed profile were similar by visual comparison.

The joint profile can be regarded as stationary signal patterns [37]. And the profile can be treated as the superposition of a series of simple sine and cosine waves. The ensemble empirical mode decomposition (EEMD) [38], as a mathematical method, has been widely used in signal processing. Thus, the EEMD can be used to decompose 


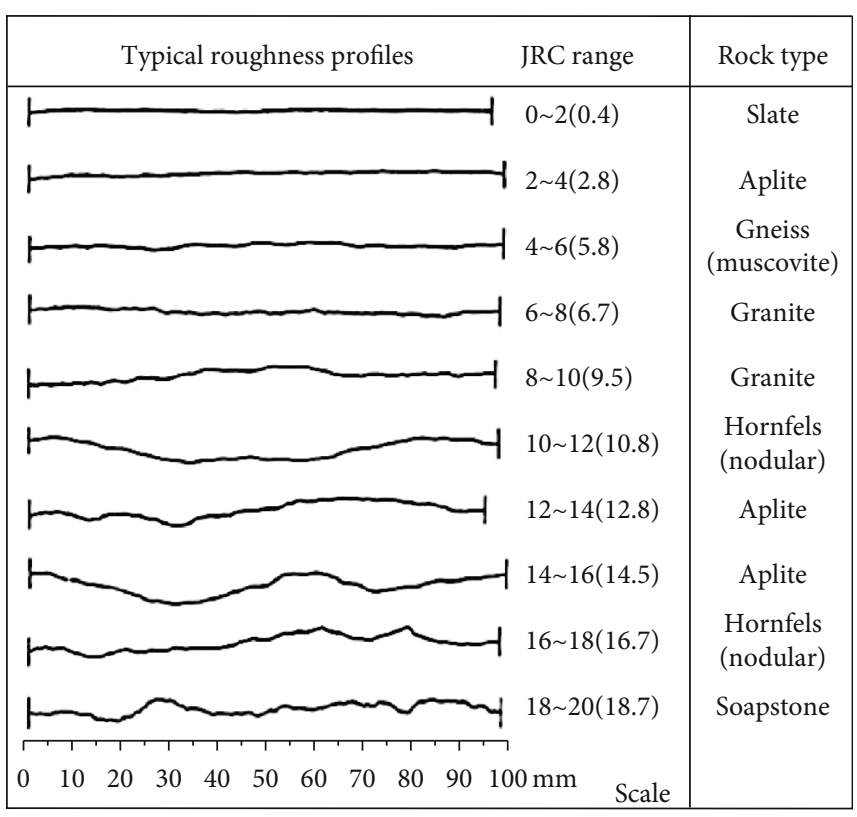

(a)

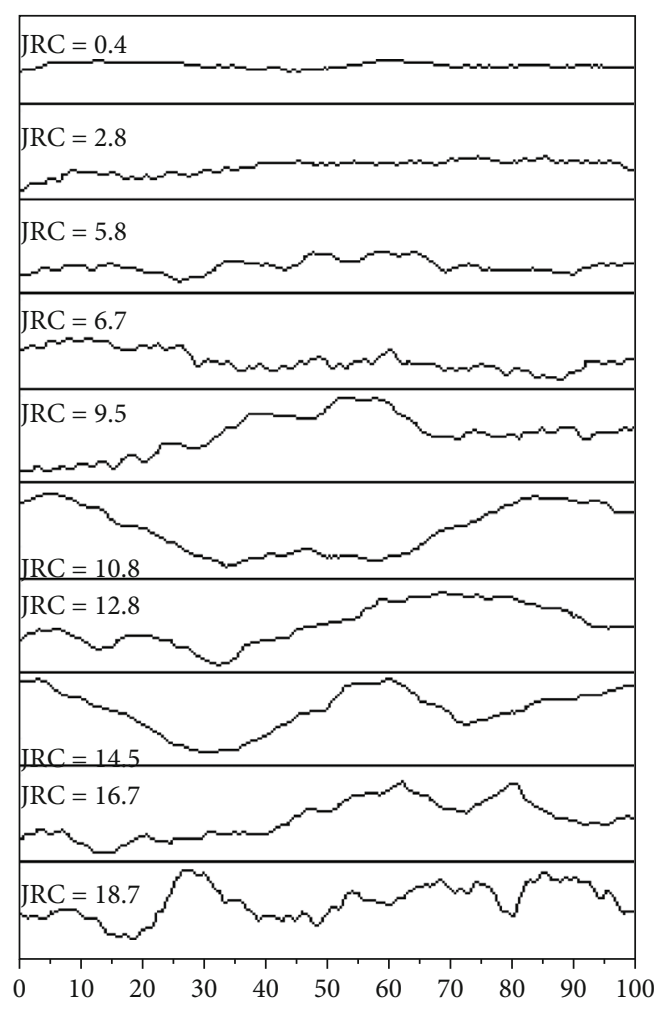

(b)

FIgURE 1: (a) The picture from Barton. (b) The picture reconstructed by the gray-scale image method.

the joint profile. The empirical mode decomposition (EMD) also can be used in signal processing. Unfortunately, the mode mixing will appear when using the EMD in signal processing. However, the EEMD can avoid the mode mixing by add white noise series in the corresponding IMFs. And the additional white noise series can erase each other in the final mean of the corresponding IMFs. The IMFs will stay within the natural dyadic filter windows, and this way can reduce the probability of mode mixing significantly and preserve the dyadic property. The proposed EEMD is developed as follows [39]: (1) add a white noise series to the target data, (2) decompose the data with added white noise into IMFs, (3) repeat steps 1 and 2 but with different white noise series, and (4) obtain the (ensemble) means of corresponding IMFs of the decompositions as the final result.

Like wavelet analysis [23], EEMD only decomposes the signal into approximate and detailed components. In order to decompose the standard roughness into primary asperity (waviness) and secondary asperity (unevenness), the cut-off level criterion with a clear mathematical definition is still needed. According to the description by the International Society of Rock Mechanics and Rock Engineering (ISRM), the waviness is defined by the dominating and large-scale overall wavy surface undulation to reflect the macroscopic fluctuations of the surface morphology, and the unevenness is defined by the generally randomly distributed small-scale unevenness. When the decomposition level is low, as the decomposition level increased, the approximate component became closer and closer to the macroscopic fluctuation in the standard roughness profile. And the approximate com- ponent is still similar to the standard roughness profile. However, when the decomposition level exceeded a certain level, part of the macroscopic fluctuation features was extracted as detailed components, and the similarity between the approximate component and the standard roughness profile declined rapidly, so the similarity can be chosen as a criterion to determine the cut-off level. In this paper, cosine similarity is used to judge the similarity between the approximate components and the original standard roughness profile because the unevenness can be regarded as a nonstationary random process following the Gaussian distribution [40]. In this study, the Kolmogorov-Smirnov (K-S) test [41] was chosen to verify the distribution of the unevenness.

2.1.2. The Decomposition Result of the Standard Roughness Profile. Combining the EEMD and the cut-off level criterion, the waviness and unevenness can be decomposed from the standard roughness profile, as shown in Figure 2. It can be seen that the waviness is characterized by large amplitude and low frequency, which can reflect the macroscopic fluctuation of the standard roughness profile, and the unevenness is characterized by small amplitude and high frequency. The characteristics of the waviness and the unevenness correspond to the qualitative description given by the ISRM, which means that the method which combines the EEMD and the cut-off level criterion can be used to decompose the standard roughness profile.

2.2. Joint Specimen Preparation and Test Plan. Considering the difficulty by the traditional way, such as tensile fracture, 

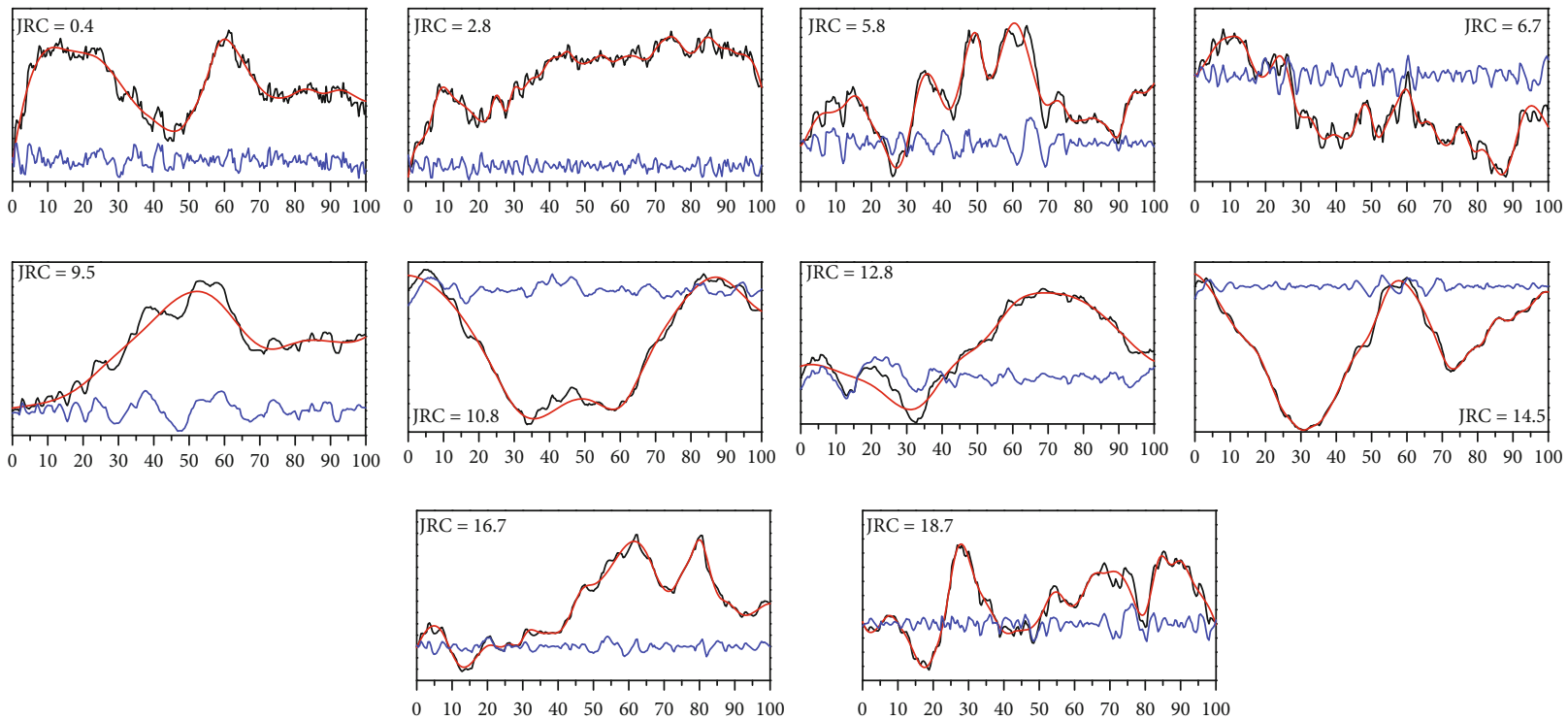

- Original

_ Waviness

__ Unevenness

FIGURE 2: The decomposition result of the standard roughness profile.

saw flat joint with undulating or irregular surface, and silicon cast of the natural or stylized joint to produce large number of joint specimens with the same morphology, the 3D rigid engraving method $[42,43]$ was proposed in this study; this method can prepare a large number of joint specimens with the same morphology by rock material. Based on the digitized profile, the joint specimen containing standard roughness profile and the specimen containing only waviness were sculpted by the digital-control engraving machine (MK-6060). As shown in Figure 3, this machine is composed of the computer control system, spindle, operating table, cooling water circulation system, and milling cutter. The positioning accuracy of the spindle of this equipment is $0.1 \mathrm{~mm}$. In order to ensure the accuracy of the joint surface, the distance between the engraving paths is set to $0.2 \mathrm{~mm}$, and the diameter of the cutter head is $0.4 \mathrm{~mm}$ in this study.

The engraving process can be divided into 4 steps, just as shown in Figure 4.

$5^{\#} \sim 10^{\#}$ standard roughness profile was chosen as initial surface morphology in this study. A total of 40 sets of joint specimens were prepared with the same raw material (red sandstone) whose mechanical parameter is shown in Table 1. Among these specimens, there are two types of specimen including only the waviness and specimen including the waviness and the unevenness.

A total of 40 sets of the joint specimen were subjected to the compression shear test, and the test plan is shown in Table 2. Three normal stresses (0.0125UCS, 0.05UCS, and $0.1 \mathrm{UCS}$ ) were applied to the joint specimen which initial roughness coefficients equal to $9.5,14.5,16.7$, and 18.7.Four normal stresses (0.0125UCS, 0.05UCS, 0.1UCS, and $0.2 \mathrm{UCS}$ ) were subjected to the joint specimen which initial roughness coefficients equal to 10.8 and 12.8 . In this study, the normal stress whose ratio to the uniaxial compressive strength is not more than 0.2 is regarded as low normal stress.

\subsection{Test Procedure}

2.3.1. Direct Shear Apparatus. The YZW-30A microcomputercontrolled electronic rock direct shear apparatus was adopted in this study. its maximum axial (tangential) load is $250 \mathrm{kN}$, and the load way includes displacement control and stress control, as shown in Figure 5(a). Thet loading process can be divided into two steps, normal stress loading and shear stress loading. At the normal stress loading process, the load rate is $0.3 \mathrm{~mm} / \mathrm{min}$. When the normal stress reaches the target value, the shear stress loading starts with a load rate of $0.3 \mathrm{~mm} / \mathrm{min}$ until the shear displacement reaches $8 \mathrm{~mm}$. Both normal stress loading and shear stress loading methods are displacement control methods.

2.3.2. Acoustic Emission Monitoring System. The acoustic emission monitoring system (Express-8, PAC) was used to monitor the damage during the whole shear process, as shown in Figure 5(b). It consists of an 8-channel acoustic emission signal acquisition system (Express-8), 4 preamplifiers (Figure 5(b), 2), 4 sensors (Figure 5(b), 3), and an acoustic emission signal processing system (AEWin). The AE sensors have a resonant frequency of $140 \mathrm{kHz}$ and operating frequency range from 125 to $400 \mathrm{kHz}$. In order to eliminate the influence of noise generated by the test apparatus, the threshold was set to be $40 \mathrm{~dB}$. The data acquisition frequency was set as $5 \mathrm{MHz}$. Four sensors were adhered on the lower part of the joint specimen. The distance between the probe and the bottom of the sample is about $35 \mathrm{~mm}$, and the distance from the left and right sides of the joint specimen was both $10 \mathrm{~mm}$, respectively, and the position can be seen in 

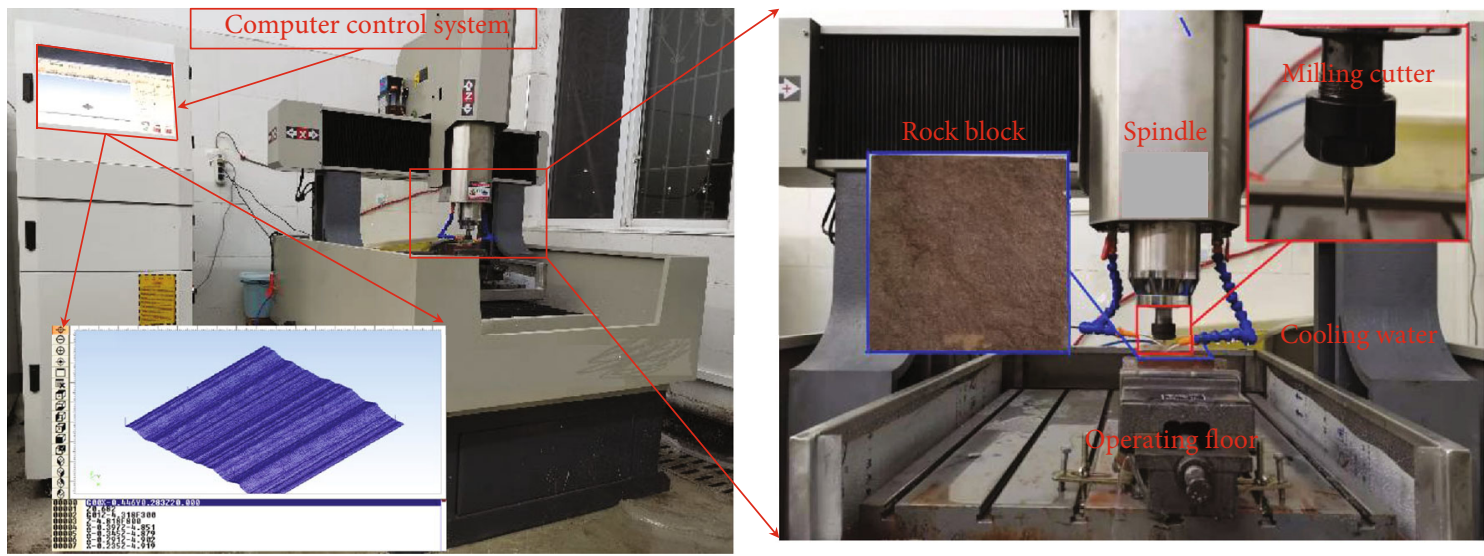

FIGURE 3: The 3D digital-control engraving machine.
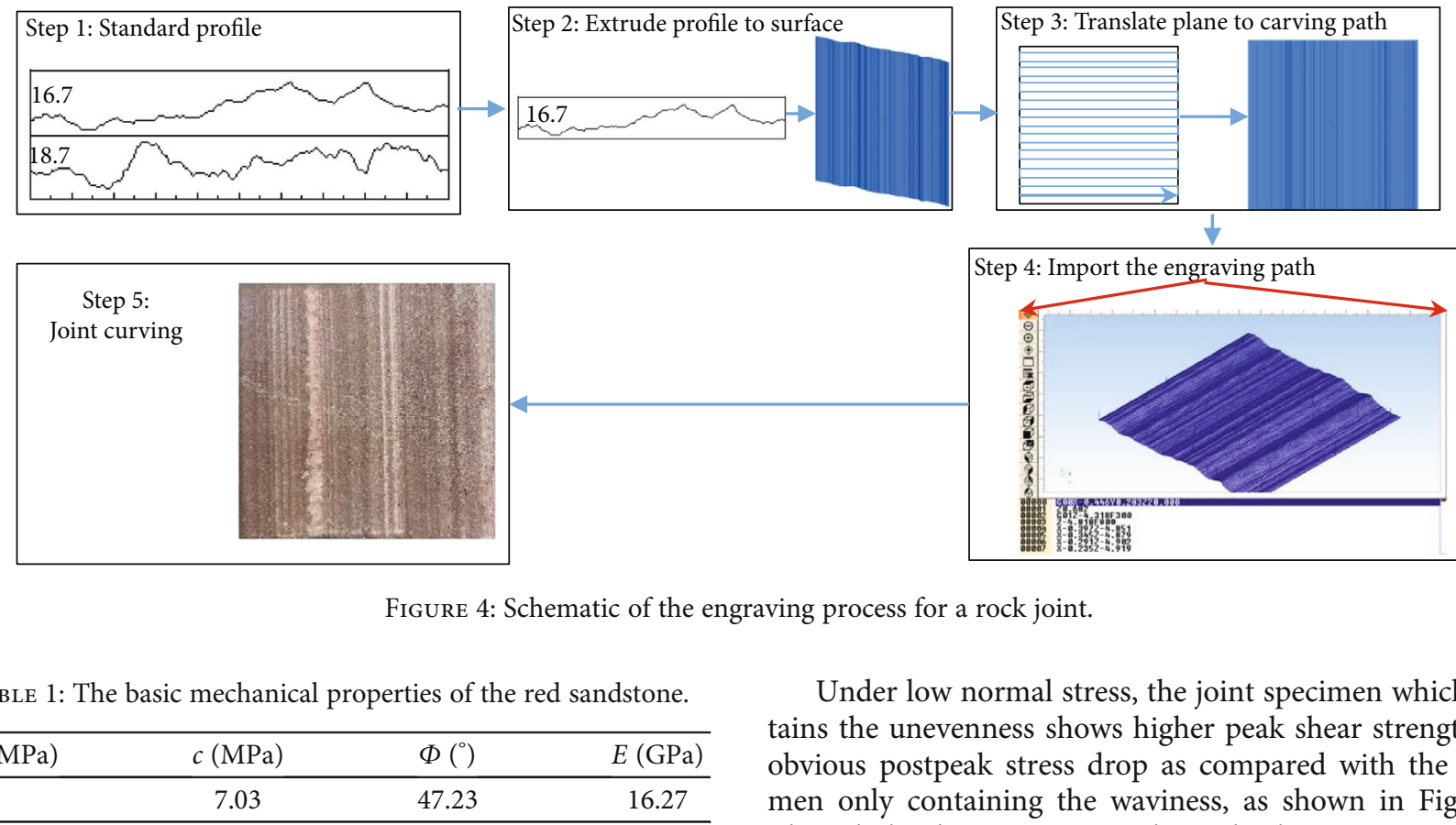

Figure 5(b), 4. In addition, a thin layer of Vaseline was applied to the interface between the rock specimen and the AE sensors for good acoustic coupling.

2.3.3. Surface Damage Characterization. A 3D light scanner (Cooper-Pro, Thunk3d, as shown in Figure 5(c)) was used to measure the surface morphology joint specimen before and after shear. The single frame accuracy, scanning range, and scanning speed of this scanner are $40 \mu \mathrm{m}, 200 \mathrm{~mm}$, and $0.3 \mathrm{~s}$, respectively.

\section{Results and Analysis}

\subsection{Test Result}

3.1.1. Shear Behaviours. The shear stress against shear displacement for all joint specimens is shown in Figure 6.

Under low normal stress, the joint specimen which contains the unevenness shows higher peak shear strength and obvious postpeak stress drop as compared with the specimen only containing the waviness, as shown in Figure 6. The whole shear stress vs. shear displacement curve can be divided into 3 sections, climbing zone, gnawing zone, and slip zone. The whole curve only includes the climbing zone and the slip zone for the joint specimen only containing waviness. When the normal stress was 9.6 MPa, the postpeak stress drop became obvious for the joint specimen only containing waviness, and the whole curve also can be divided into 3 sections, climbing zone, gnawing zone, and slip zone, as shown in Figures 6(b) and 6(c). Under low normal stress, the difference of mechanical behaviour between the specimen containing unevenness and the specimen only containing waviness mainly appeared in the prepeak nonlinear stage and the postpeak stage.

3.1.2. Damage Characteristic. Figure 7 shows the joint surface which has a roughness coefficient equal to 9.5 after shear under different normal stress. We can find that the colour of the damaged area is lighter than the undamaged area. So the damaged area difference between the joint specimen 
TABLe 2: The plan for the direct shear test.

\begin{tabular}{|c|c|c|}
\hline Joint roughness & Asperity order & Normal stress \\
\hline \multirow{2}{*}{$\mathrm{JRC}=9.5$} & Waviness+unevenness & $0.6 \mathrm{MPa}, 2.4 \mathrm{MPa}, 4.8 \mathrm{MPa}$ \\
\hline & Waviness & $0.6 \mathrm{MPa}, 2.4 \mathrm{MPa}, 4.8 \mathrm{MPa}$ \\
\hline \multirow{2}{*}{$\mathrm{JRC}=10.8$} & Waviness+unevenness & 0.6 MPa, 2.4 MPa, 4.8 MPa, 9.6 MPa \\
\hline & Waviness & $0.6 \mathrm{MPa}, 2.4 \mathrm{MPa}, 4.8 \mathrm{MPa}, 9.6 \mathrm{MPa}$ \\
\hline \multirow{2}{*}{$\mathrm{JRC}=12.5$} & Waviness+unevenness & $0.6 \mathrm{MPa}, 2.4 \mathrm{MPa}, 4.8 \mathrm{MPa}, 9.6 \mathrm{MPa}$ \\
\hline & Waviness & $0.6 \mathrm{MPa}, 2.4 \mathrm{MPa}, 4.8 \mathrm{MPa}, 9.6 \mathrm{MPa}$ \\
\hline \multirow{2}{*}{$\mathrm{JRC}=14.8$} & Waviness+unevenness & $0.6 \mathrm{MPa}, 2.4 \mathrm{MPa}, 4.8 \mathrm{MPa}$ \\
\hline & Waviness & $0.6 \mathrm{MPa}, 2.4 \mathrm{MPa}, 4.8 \mathrm{MPa}$ \\
\hline \multirow{2}{*}{$\mathrm{JRC}=16.7$} & Waviness+unevenness & $0.6 \mathrm{MPa}, 2.4 \mathrm{MPa}, 4.8 \mathrm{MPa}$ \\
\hline & Waviness & $0.6 \mathrm{MPa}, 2.4 \mathrm{MPa}, 4.8 \mathrm{MPa}$ \\
\hline \multirow{2}{*}{$\mathrm{JRC}=18.7$} & Waviness+unevenness & $0.6 \mathrm{MPa}, 2.4 \mathrm{MPa}, 4.8 \mathrm{MPa}$ \\
\hline & Waviness & $0.6 \mathrm{MPa}, 2.4 \mathrm{MPa}, 4.8 \mathrm{MPa}$ \\
\hline
\end{tabular}

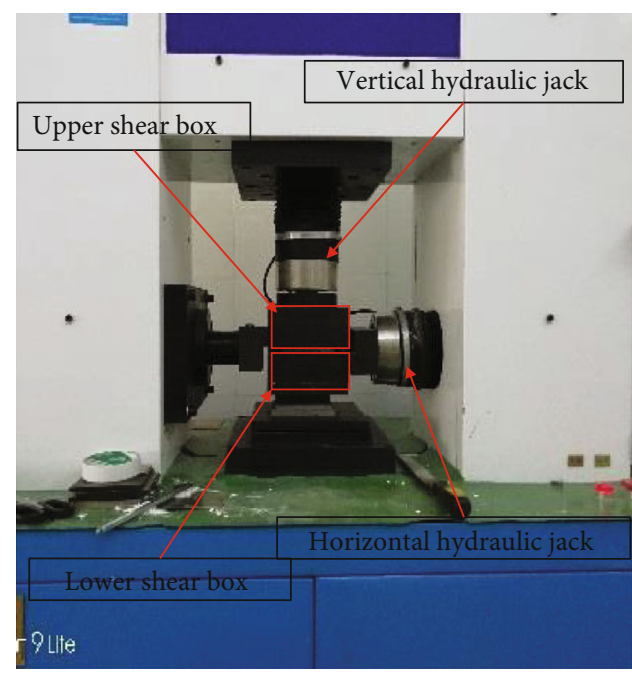

(a)

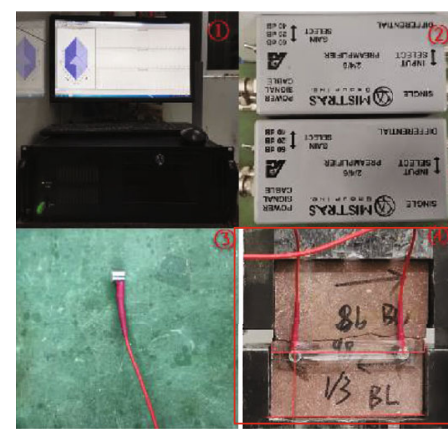

(b)

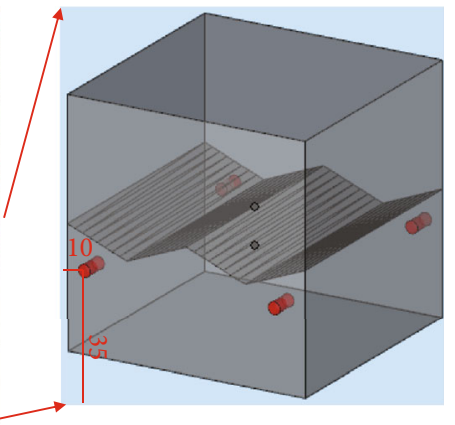

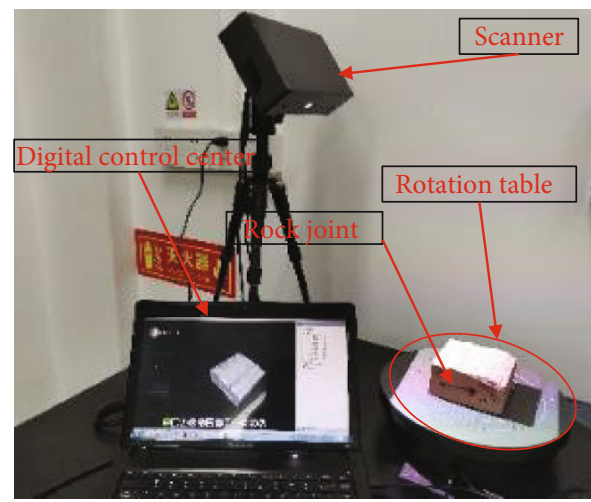

(c)

Figure 5: Test apparatuses. (a) Direct shear equipment (YZW-30A). (b) AE system (PAC Express-8). (c) 3D scan system (Cooper-Pro, Thunk3d). 


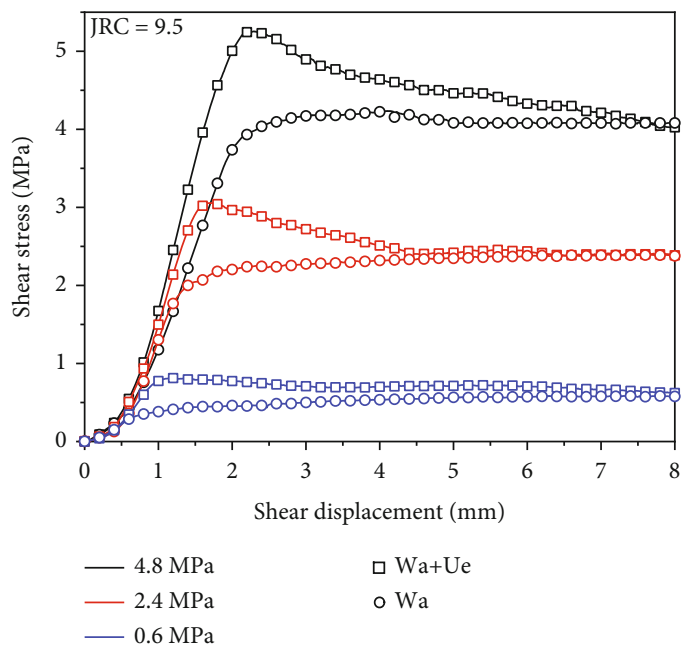

(a)

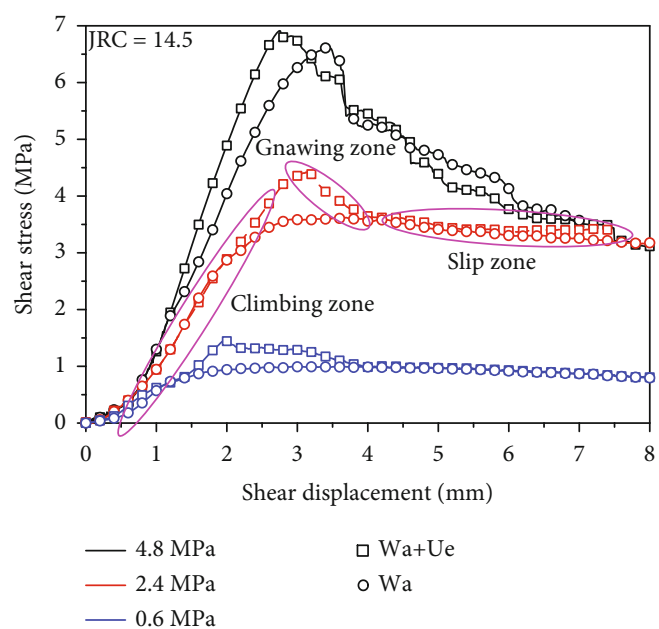

(c)

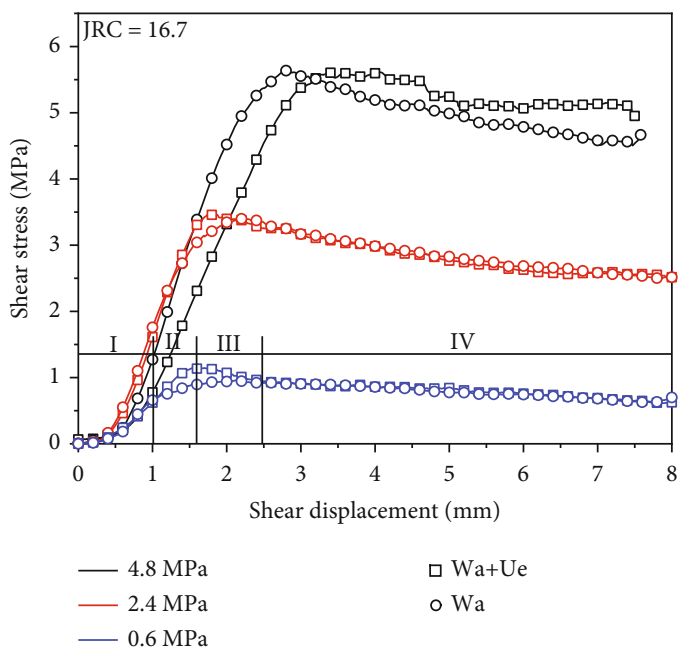

(e)

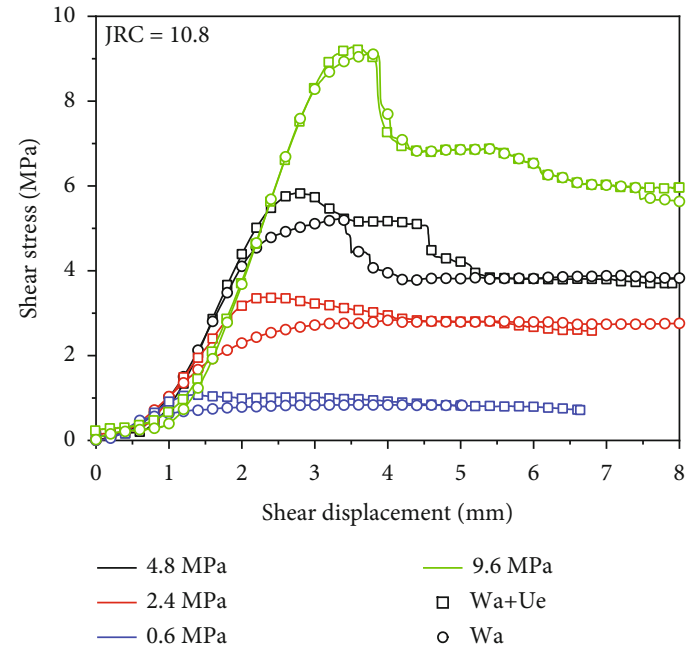

(b)

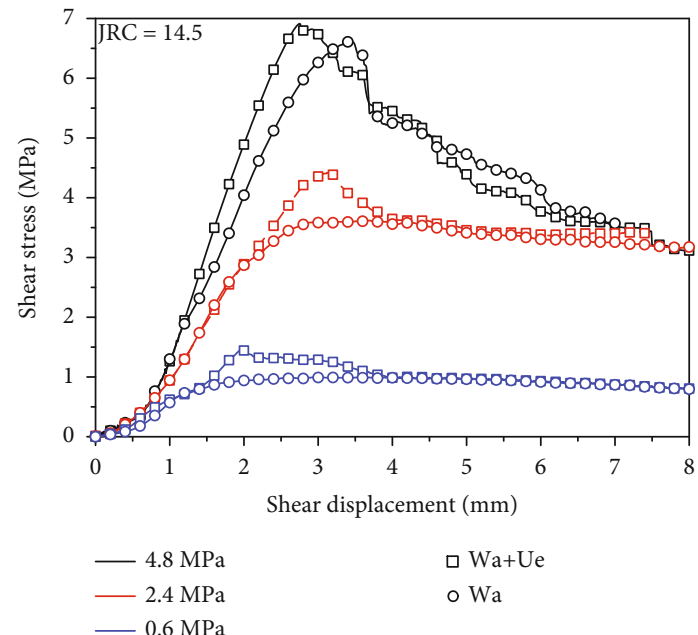

(d)

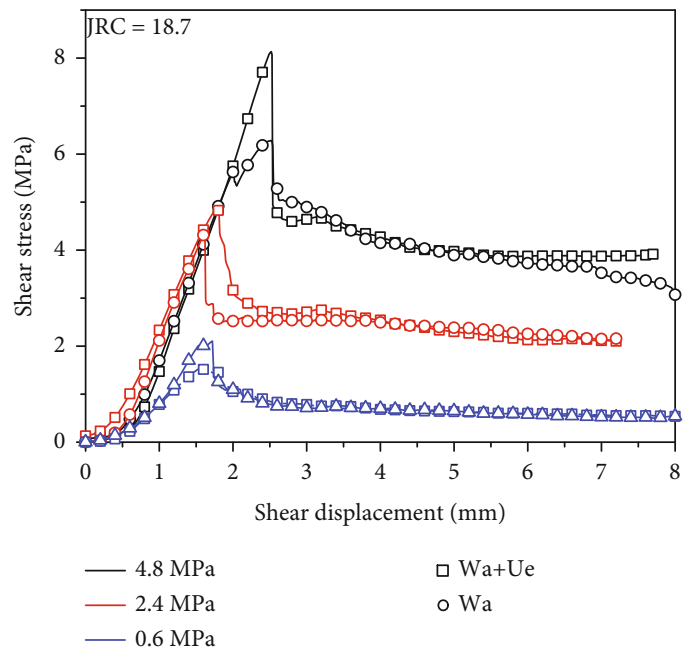

(f)

FIGURE 6: Shear stress-shear displacement curve under different normal stresses. Note: Wa means waviness; Ue means unevenness; I means the linear stage before peak shear stress; II means the nonlinear stage before peak shear stress; III means the nonlinear stage after the peak shear stress; IV means the residual stage. 
$0.6 \mathrm{MPa}$

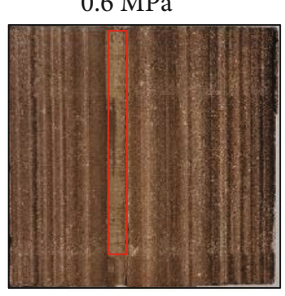

(a)

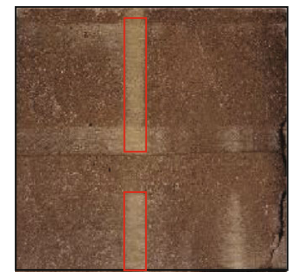

(d)

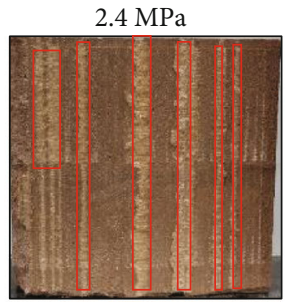

(b)

Waviness + Unevenness

(a)

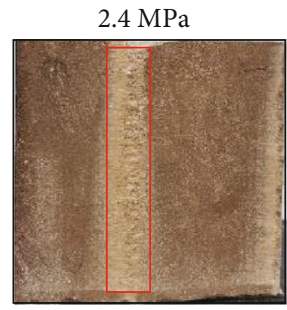

(e)

Waviness

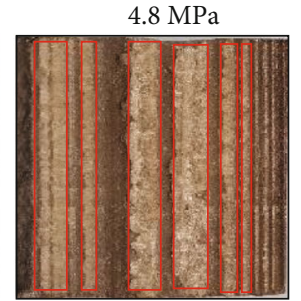

(c)

(b)

Figure 7: The joint surface after the shear test under different normal stresses.

containing unevenness and the specimen only containing waviness can be identified by visual comparison. The joint surface of the other specimen which has roughness coefficients equal to $10.8,12.8,14.5,16.7$, and 18.7 after shear under different normal stresses can be found in Appendix 1.

As shown in Figure 7, under low normal stress, there are only scratches that appear on the surface of the joint specimen only containing waviness, while there is obvious shear damage that appears on the surface of the joint specimen containing unevenness. When the normal stress was 9.6 $\mathrm{MPa}$, the surface of the joint specimen that only contains waviness also shows obvious shear damage, as shown in Appendix 1. It can be inferred that, under low normal stress, the failure mode of the joint specimen only containing waviness is dominated by sliding wear, while the joint specimen containing unevenness is dominated by shear failure. The failure mode of the joint specimen only containing waviness changes from sliding wear to shear failure as the normal stress increases. Comparing Figures 7(a)-7(c) or Figures 7(d)-7(f), it can be seen that the damaged area increased with the increase of normal stress. This means that the damage degree increases with the increase of normal stress regardless of whether the joint specimen contains unevenness or not. Comparing Figures 7(a) and 7(d), Figures 7(b) and 7(e), or Figures $7(\mathrm{c})$ and $7(\mathrm{f})$, it can be seen that the damaged area of the joint specimen containing unevenness is larger than that of the joint specimen only containing waviness. And this difference increases with the normal stress increase.

3.1.3. Acoustic Emission ( $A E$ ) Energy. The mechanical character difference is related to the damage difference between the two types of joint specimen. As shown in Figure 6, the mechanical character difference mainly appeared in the prepeak nonlinear stage and the postpeak stage. However, the damaged area and damage volume just reflect the damage degree at the end of the shear process. AE energy, a parameter which can reflect the damage generated during shear, was chosen to reflect the damage during the shear process. This section will analyse the effect of asperity order on the mechanical character of the joint specimen from the AE energy difference during the shear process.

Figure 8 shows the energy rate and the AE energy during the whole shear process. Figure 8 just shows the result of the specimen which roughness coefficient equal to 9.5; the result of the other specimen can be found in Appendix 2. It can be seen from Figure 8 that the energy rate vs. the shear displacement curve can be divided into 4 stages: nearly zero at the beginning, rising, falling rapidly, and keeping stable in the final. Correspondingly, the shear stress vs. the shear displacement can be divided into 4 stages: prepeak linear stage, prepeak nonlinear stage, postpeak stage, and residual stage. Comparing the stress stage and the energy rate stage, it can be found that different stress stages showed different energy rate characters. Prepeak linear stage: the shear stress is small, and the joint surface is still in an elastic state. Correspondingly, the energy rate is also low, which means that in this stage the joint specimen is hardly damaged. Prepeak nonlinear stage: in this stage, the shear stress increases rapidly with the increase of the shear displacement, and the specimen begins to climb along the surface. The energy will generate in the climb process, and the energy rate almost reaches the peak at the end of this stage; postpeak stage: at this stage, the shear stress decreases continually. And the decrease rate gradually decreases with the shear displacement increase. At the beginning of this stage, a large number of asperities were damaged, which produce a lot of acoustic emission events, 

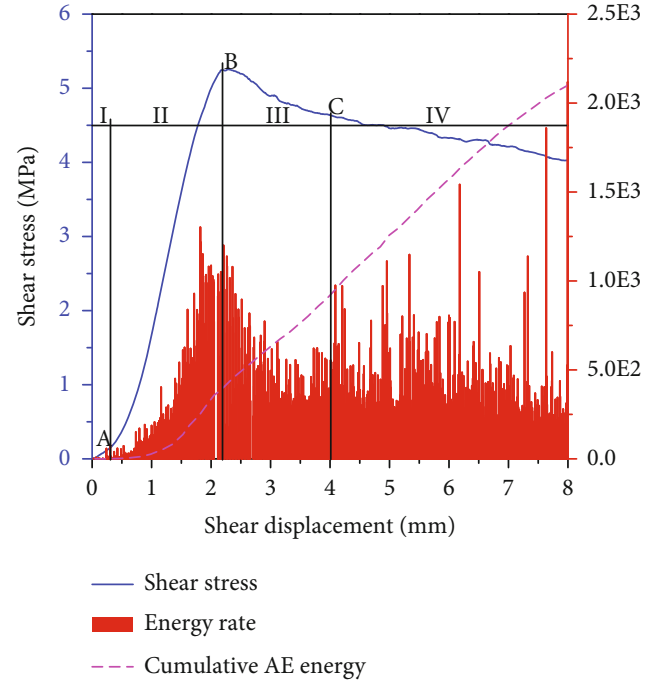

(a) $0.6 \mathrm{MPa}$ (waviness+unevenness)

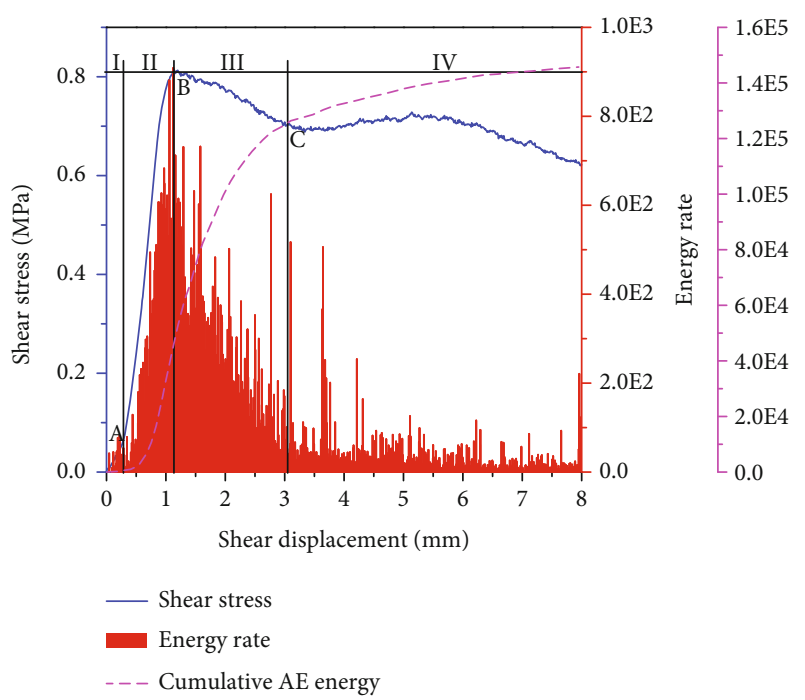

(c) $4.8 \mathrm{MPa}$ (waviness+unevenness)

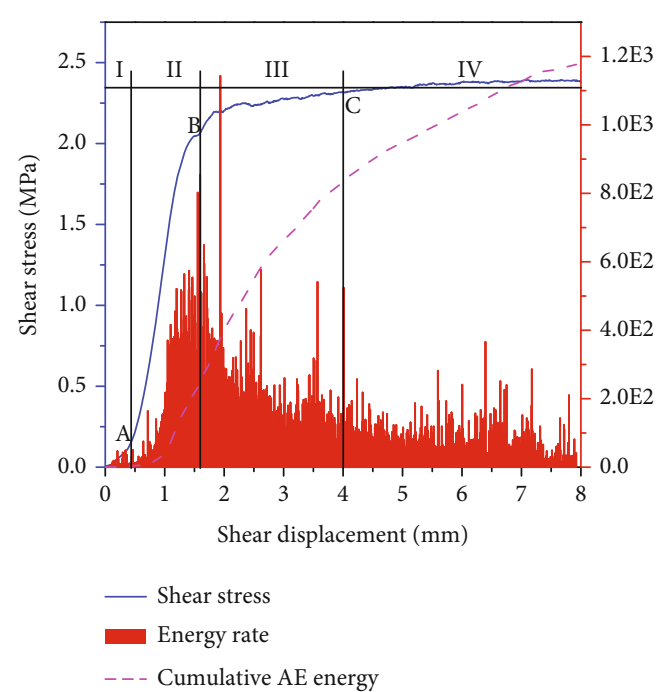

(e) $2.4 \mathrm{MPa}$ (waviness)
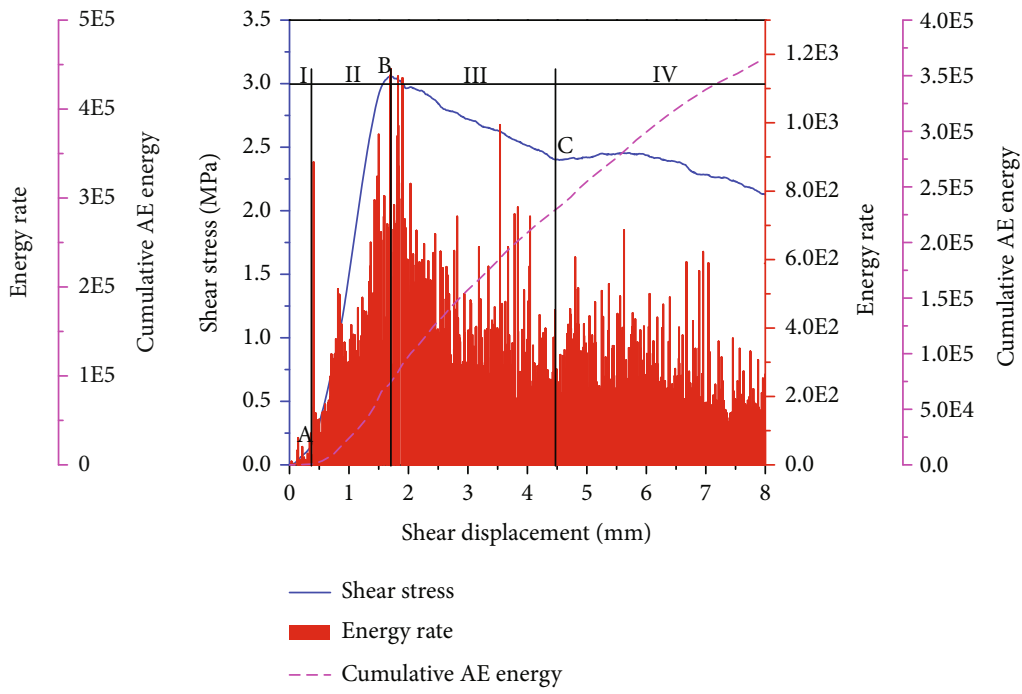

(b) $2.4 \mathrm{MPa}$ (waviness+unevenness)

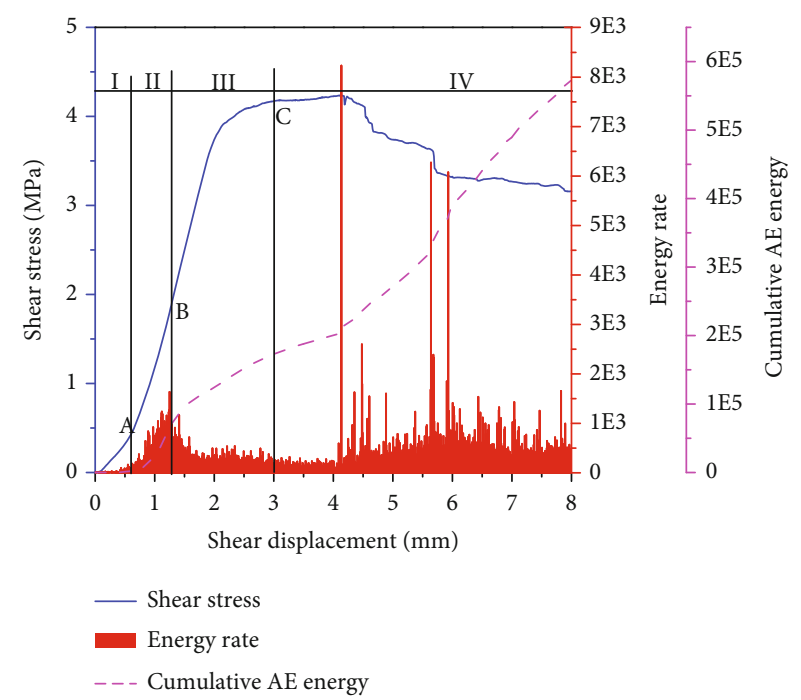

(d) $0.6 \mathrm{MPa}$ (waviness)

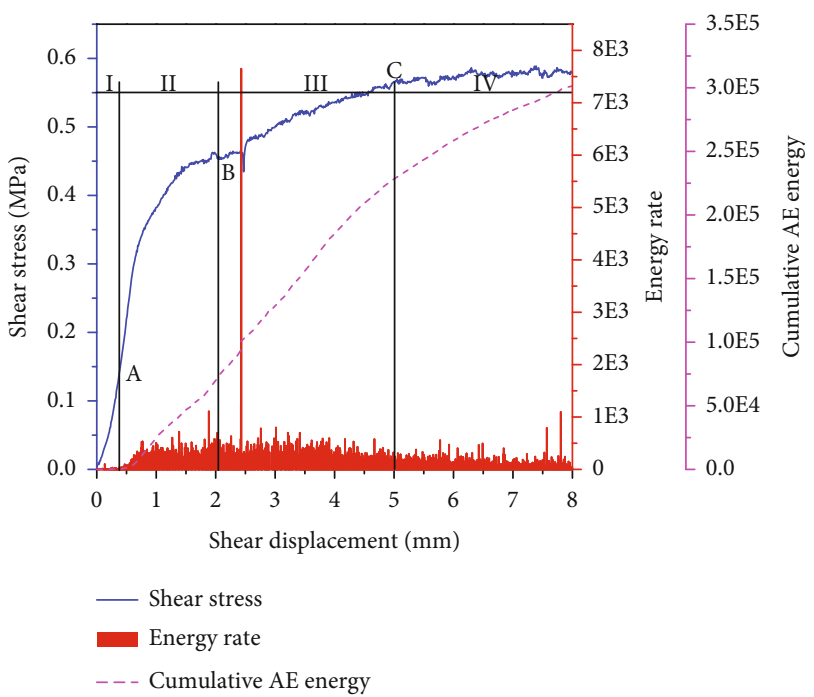

(f) $4.8 \mathrm{MPa}$ (waviness)

FIGURE 8: Variation of AE parameters (energy rate and cumulative AE energy) with shear displacement for rock joint specimen $(J R C=9.5)$. 


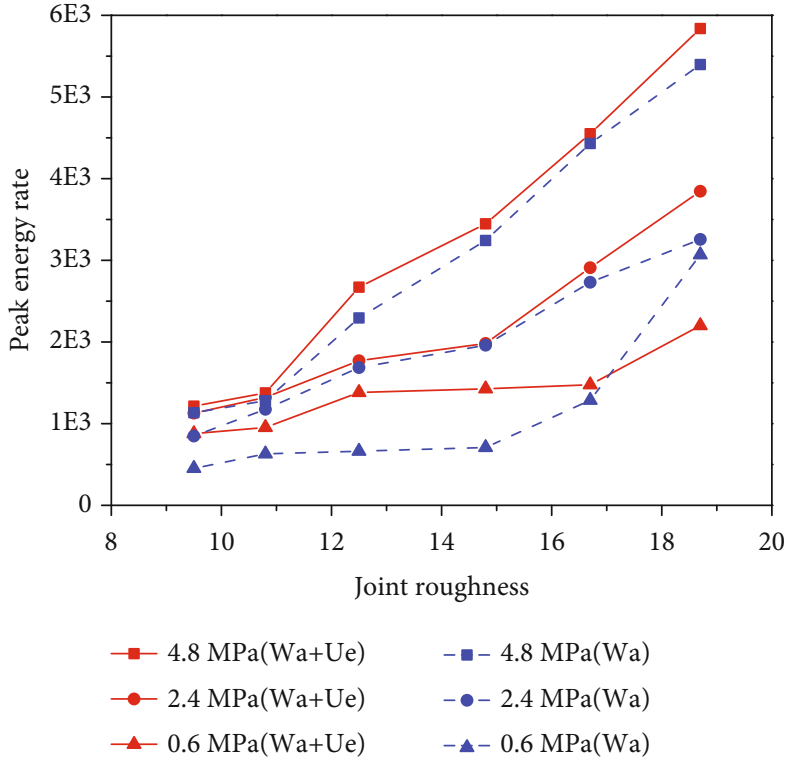

(a)

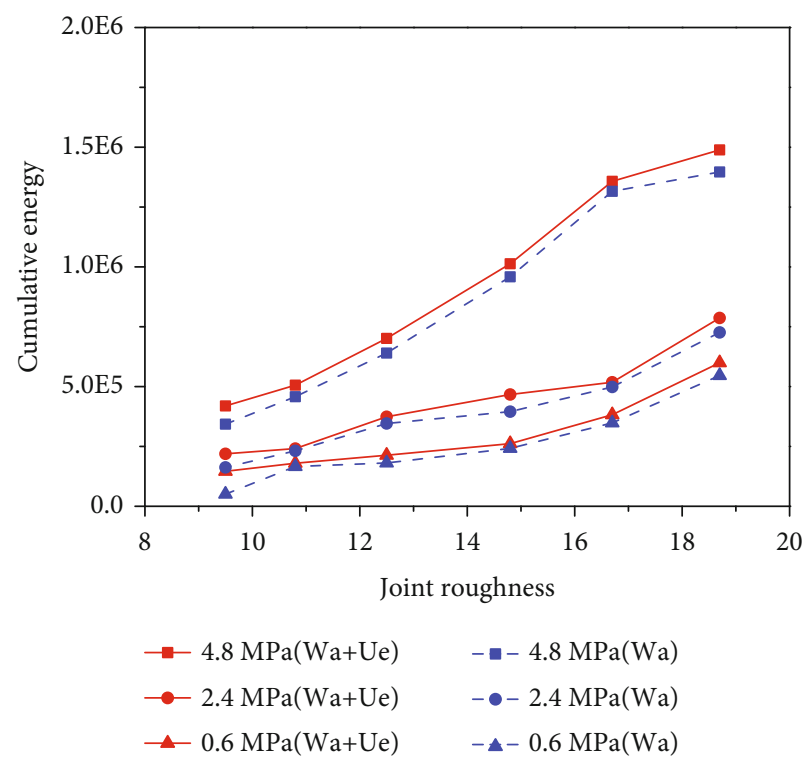

(b)

FiguRE 9: AE parameter for different specimens under different normal stresses: (a) peak energy rate and (b) cumulative AE energy.

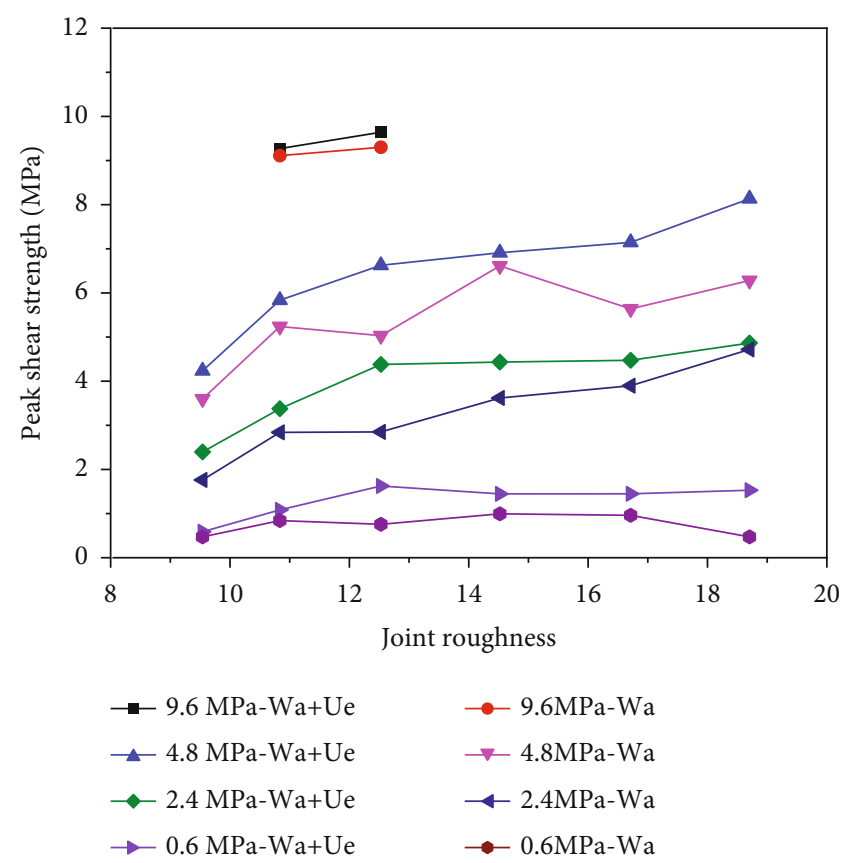

(a)

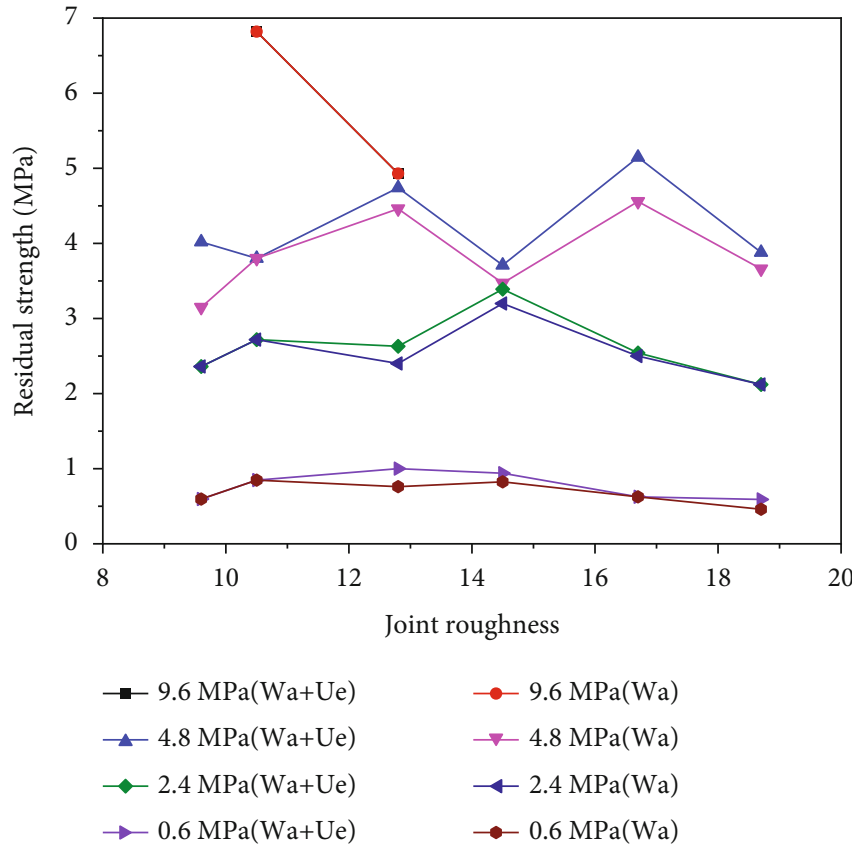

(b)

Figure 10: (a) Peak shear strength. (b) Residual shear strength. Note: Wa means waviness, and Ue means unevenness.

so the energy rate is still high. With the displacement increase, the number of the asperity which can provide resistance gradually decreased, which leads to the number of the asperity being sheared gradually decreasing. Therefore, the energy rate gradually decreased at the end of the postpeak stage. Residual stage: at this stage, the shear stress keeps stable. The asperity which can provide resistance has almost been damaged at the postpeak stage. And the contact rate is at a low level and almost unchanged. So the energy rate at this stage was basically stable at a relatively low level.

Figure 9 shows the peak energy rate and cumulative energy under different normal stresses. It can be seen that the peak energy rate and cumulative $\mathrm{AE}$ energy increased with the normal stress increases for the joint specimen with the same morphology, which indicates that the damage ratio increases with the normal stress. The peak energy rate and 
(a) Step 1: Get point cloud data

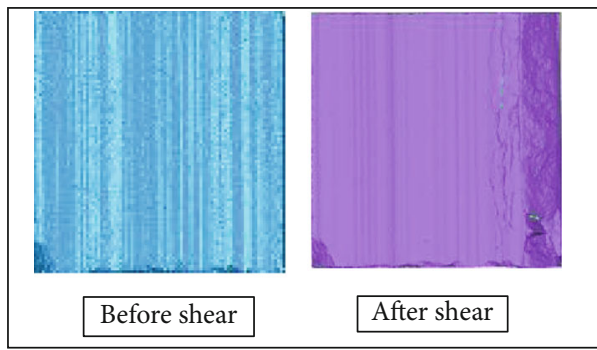

(b) Step 2: Align the point cloud data by ICP

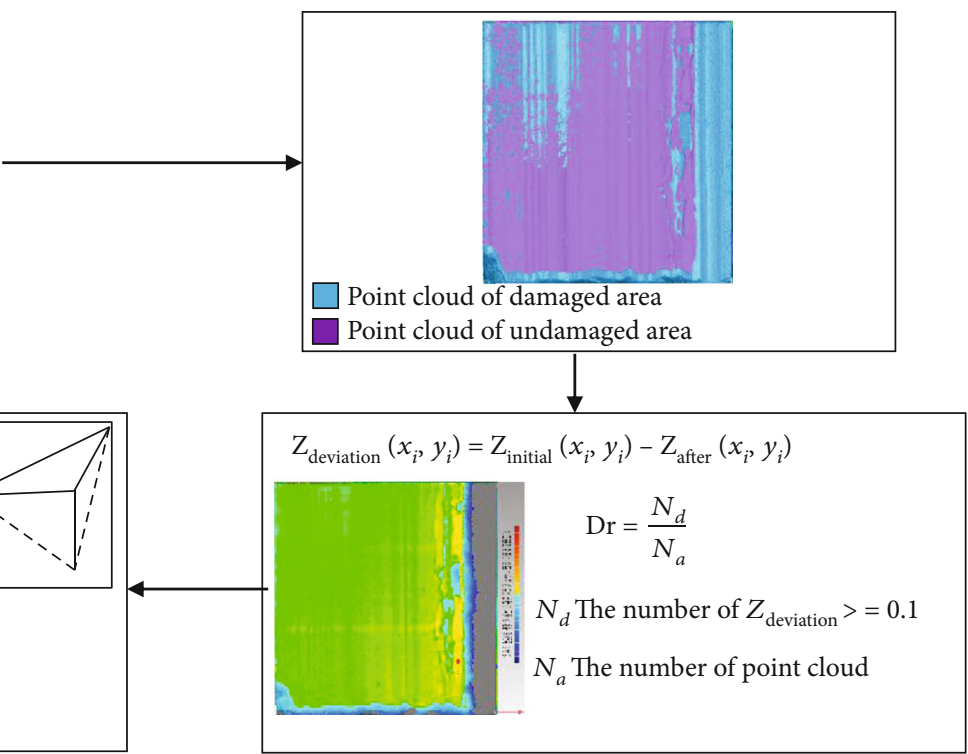

(c) Step 3: Calculate the damage area ratio

(d) Step 4: Calculate the damage volume

FIGURE 11: Schematic of calculating the damaged area ratio and damage volume.
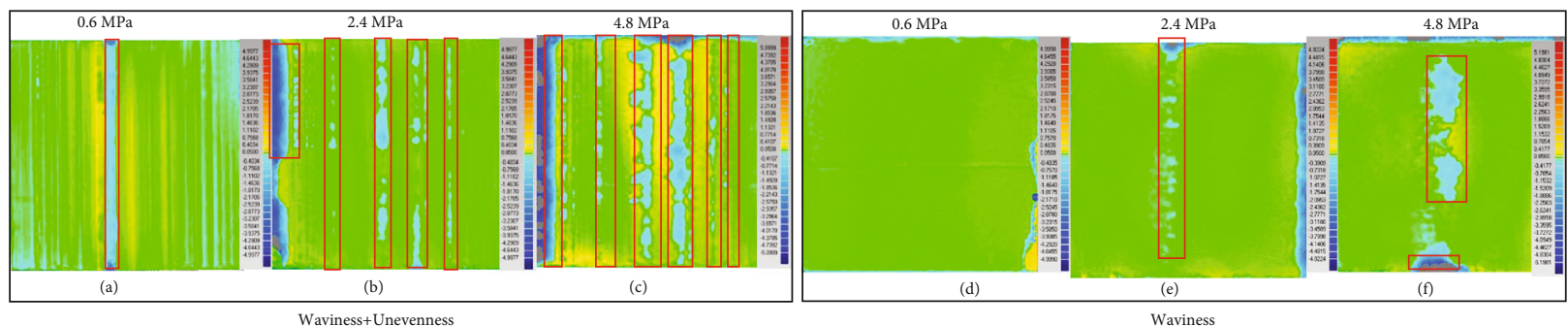

FiguRE 12: Surface height deviation under different normal stresses.

cumulative energy of the joint specimen containing unevenness were higher than those of the specimen only containing waviness, which means that the damage degree of the joint specimen containing unevenness was higher than that of the joint specimen only containing waviness.

\subsection{Result Analysis}

3.2.1. Asperity Order Effect on the Shear Strength. Figure 10 shows the peak shear strength and residual shear stress for different specimens under different normal stresses. It can be seen that (1) the peak shear strength and the residual shear stress of two types of joint specimens both increased with the surface roughness increase under the same normal stress. (2) The peak shear strength of the joint specimen containing unevenness was higher than that of the specimen only containing waviness. This difference in peak shear strength increased as the normal stress increased under low normal stress, which means that unevenness plays a control role in the mechanical behaviour under the low normal stress. When the normal stress is large, the difference in peak shear strength is almost zero, which means that waviness plays a control role in the mechanical behaviour under large normal stress.
The peak shear strength of the joint specimen was related to the average inclination angle of the surface [10, 44, 45]. According to the description by the ISRM, waviness is defined by the dominating and large-scale overall wavy surface undulation to reflect the macroscopic fluctuations of the surface morphology, and unevenness is defined by the generally randomly distributed small-scale unevenness. Comparing the waviness and the unevenness, the unevenness's inclination angle is larger than the waviness's. So the average inclination angle of the joint specimen containing unevenness is greater than that of the specimen only containing waviness. Therefore, the peak shear strength of the joint specimen containing unevenness is greater than that of the sample only containing waviness. At the residual stage, almost all the unevenness was cut off and the contact ratio in the residual stage was reduced due to the dilatancy; this makes the surface morphology of the joint specimen containing unevenness be similar to that of the joint sample only containing waviness.

3.2.2. Asperity Order Effect on the Damage Ratio. The mechanical character difference is related to the damage difference between the two types of the joint specimen. In order to characterize the damage difference between the two types 


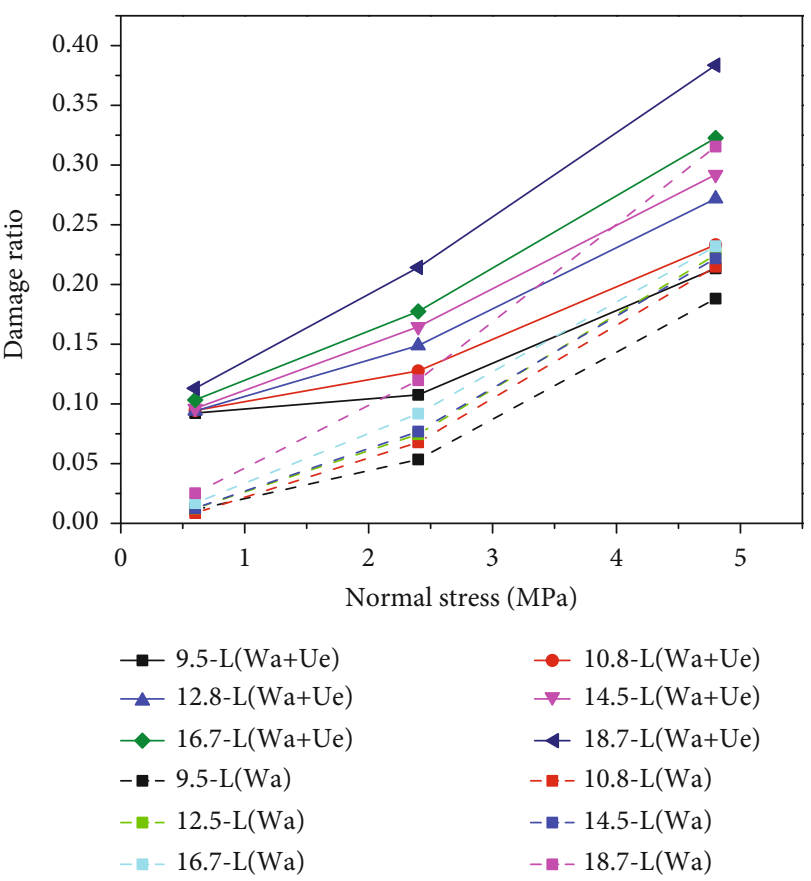

FIGURE 13: The damaged area ratio of the joint specimen with different asperity order under different normal stresses.

of the joint specimen, the damaged area and damage volume were calculated in this section. The morphology of the damaged area is complex, so it is not easy to quantify the damaged area accurately through two-dimensional (2D) image analyses. In this study, a new method to quantify the joint damage ratio and damage volume was proposed [46]. The realization of this method can be divided into three steps [47]: (1) get the point cloud data of the joint surface before and after shear, (2) align the point cloud data of the joint surface before and after shear by the ICP algorithm, and (3) calculate the height deviation and damage volume by the Matlab code; the code can be found in Appendix 3. And the steps are shown in Figure 11.

Figure 12 shows the height deviation of the joint specimen which roughness equal to 9.5. The result of the other specimens can be found in Appendix 1.

Comparing Figures 12 and 7, it can be seen that the damaged area consists of the area in which the height deviation is larger. Generally, 5 6 measurements were needed to obtain the whole morphology. And errors can also occur during the alignment process. The combined three-dimensional error is difficult to be quantified. According to the accuracy of the scanning equipment and the test process, the test accuracy is set to $0.1 \mathrm{~mm}$, which is consistent with Indraratna et al. [48] and Gui et al.'s [49] study. Based on this rule, the damaged area ratio was calculated.

Figure 13 shows the damaged area ratio of the joint specimen with different asperity order under different normal stress. It can be seen from Figure 13 that the damaged area ratio increased with the increase of the normal stress. The damaged area and the growth rate of the damaged area ratio of the joint specimen containing unevenness were greater than those of the joint specimen only containing waviness,

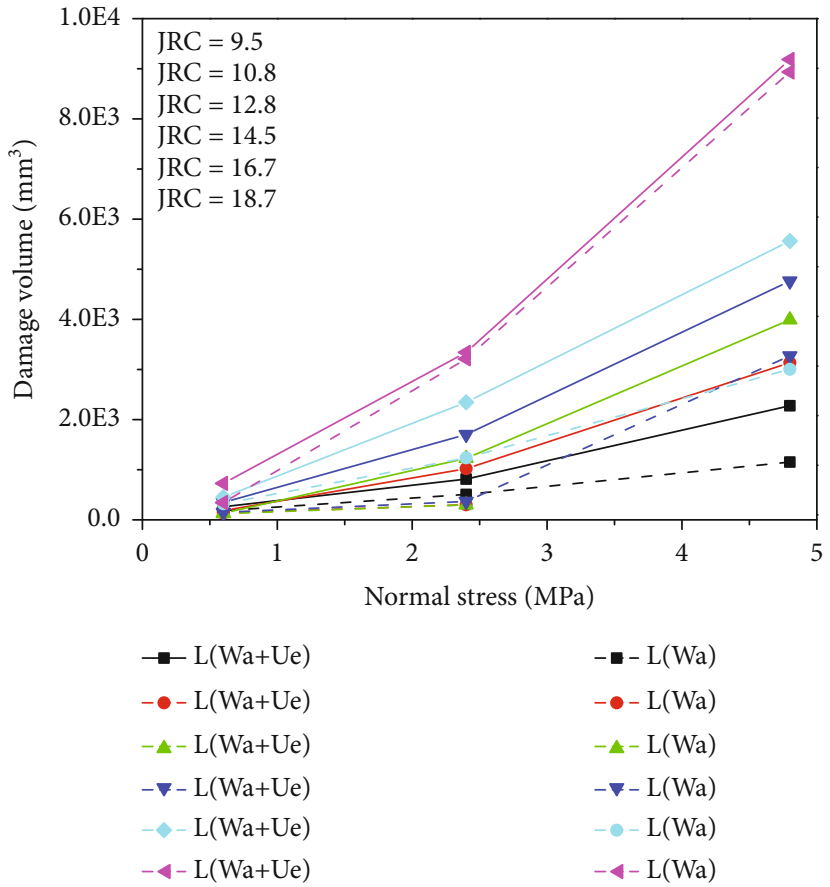

FIgURE 14: The damage volume of rock joint with different asperity order under different normal stresses.

under the condition of the same initial morphology. Thus, it can be concluded that, compared with the waviness, the unevenness is more prone to damage under low normal stress, resulting in a higher damaged area.

The damaged area ratio just reflects the proportion of the damaged area. It is difficult to reflect the damage degree accurately. The damage volume can reflect the damage degree in 3 dimensional, so it can reflect the damage degree more accurately compared with the damaged area. The calculation method of joint specimen damage volume mainly includes the following steps: (1) align the point cloud data before and after cutting by ICP iteration method and (2) triangulate the point data by the Delaunay triangulation method. In this paper, the joint surface asperities were discretized into triangles. $\triangle \mathrm{ABC}$ represents the asperity before shearing, and $\triangle \mathrm{A}^{\prime}$ $\mathrm{B}^{\prime} \mathrm{C}^{\prime}$ represents the asperity after shearing, as shown in Figure 11(d). The damage volume of the joint specimen is the sum of these volumetric elements $V_{\mathrm{ABC}-\mathrm{A}^{\prime} \mathrm{B}^{\prime} \mathrm{C}^{\prime}}$. Among them, $V_{\mathrm{ABC}-\mathrm{A}^{\prime} \mathrm{B}^{\prime} \mathrm{C}^{\prime}}$ is calculated by Equations (1) and (2). The damage volume of the joint specimen is calculated by Equation (3).

$$
V_{\mathrm{ABC}-\mathrm{A}^{\prime} \mathrm{B}^{\prime} \mathrm{C}^{\prime}}=V_{\mathrm{A}^{\prime} \mathrm{B}^{\prime} \mathrm{C}^{\prime}-\mathrm{A}}+V_{\mathrm{AB}^{\prime} \mathrm{C}^{\prime}-\mathrm{B}}+V_{\mathrm{ABC}-\mathrm{C}^{\prime}},
$$

$$
V_{\mathrm{ABC}-\mathrm{A}^{\prime} \mathrm{B}^{\prime} \mathrm{C}^{\prime}}=\frac{1}{6} *\left|\begin{array}{cccc}
1 & 1 & 1 & 1 \\
\mathrm{x}_{a} & x_{b} & x_{c} & x_{d} \\
y_{a} & y_{b} & y_{c} & y_{d} \\
z_{a} & z_{b} & z_{c} & z_{d}
\end{array}\right|,
$$




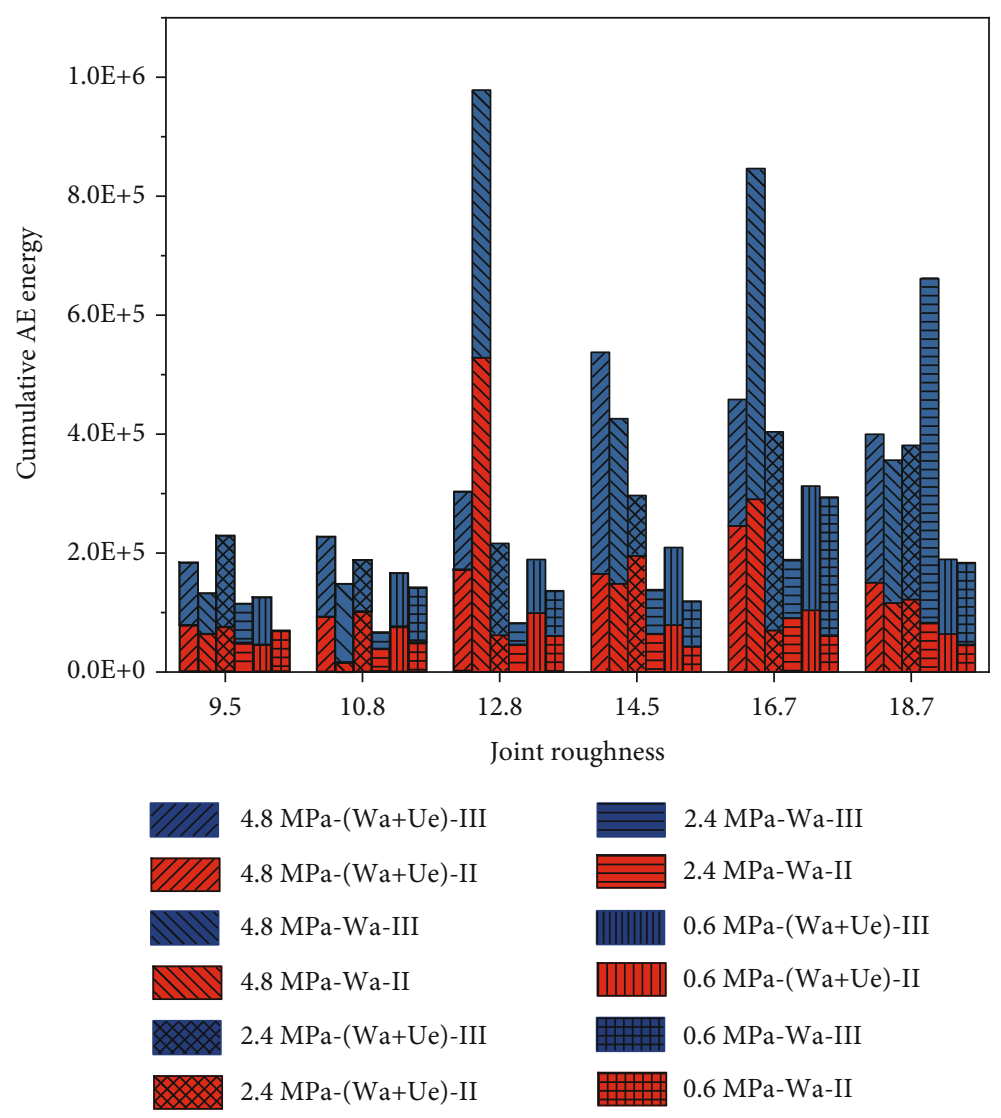

Figure 15: The cumulative AE energy in the second and third stages.

$$
V=\sum V_{\mathrm{ABC}-\mathrm{A}^{\prime} \mathrm{B}^{\prime} \mathrm{C}^{\prime}}
$$

Based on the above method, the damage volume of the joint specimen can be calculated, and the calculation result is shown in Figure 14.

It can be seen that the damage volume increased with the increase of the normal stress; the damage volume of the specimen containing unevenness is larger than that of the joint specimen only containing waviness, and this difference increases with the normal stress increase. As shown in Figure 3, the average inclination angle of the specimen containing unevenness was higher than that of the specimen only containing waviness. Only the asperity's apparent dip angle is greater than a certain value; the asperity will be damaged during shearing [50]. Thus, compared with the waviness, the unevenness is more prone to be damaged. With the increase of the normal stress, more and more unevenness undergo shear failure, while the joint specimen containing waviness only undergoes slip wear failure, leading to a bigger difference in damage volume.

3.2.3. Asperity Order Effect on the Damage Energy. In fact, the difference in the shear mechanical properties of these two types of joint specimens mainly appeared in the prepeak nonlinear stage and the postpeak stage (the second and third stages), as shown in Figure 6. Therefore, further research was carried out on the acoustic emission energy of these two stages. The cumulative energy of acoustic emission in the second and third stages is shown in Figure 15.

It can be seen that under the condition of the same normal stress, the damage ratio and the cumulative energy generated in the second and third stages increased with the increase of the joint roughness coefficient. The rougher the joint surface, the less probability of shear failure occurring, the higher the energy accumulated before failure, and the greater the energy released when the joint surface fails. Under the same conditions, the cumulative energy produced in the third stage was higher than that in the second stage. In the prepeak nonlinear stage, the acoustic emission energy released by the joint specimen containing unevenness was higher than that of the joint specimen only containing waviness. In the postpeak stage, the unevenness on the surface of the joint specimen was sheared, which results in the energy released in the third stage being higher than that in the second stage.

Acoustic emission $b$ value [51] is used as a characterization of the proportion of large-amplitude acoustic emission events and small-amplitude acoustic emission events in the entire section, which can be used to represent the damage degree of the joint specimen. The expression is shown in

$$
\lg N=a-b \frac{A_{\mathrm{dB}}}{20}
$$




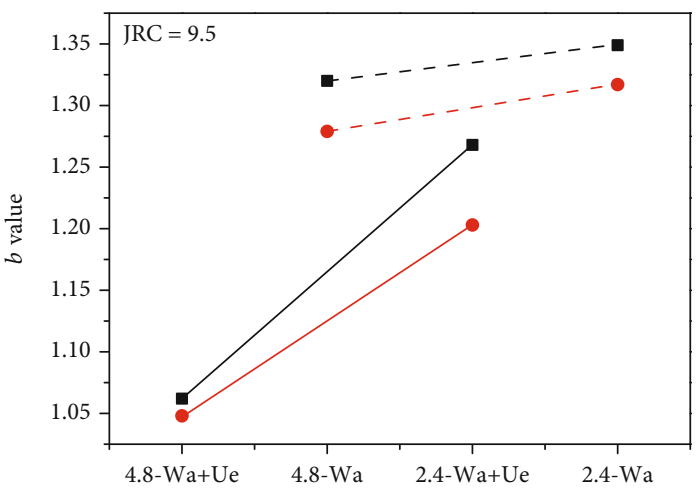

- Period-II

- Period-III

(a)

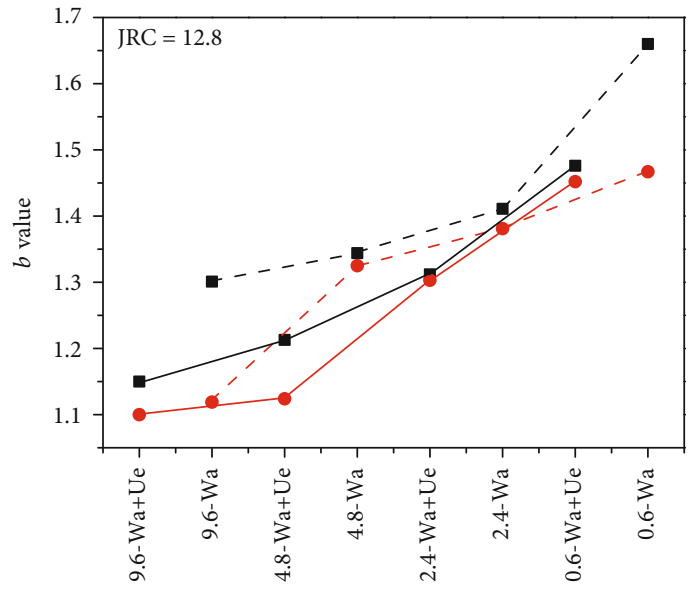

- Period-II

- Period-III

(c)

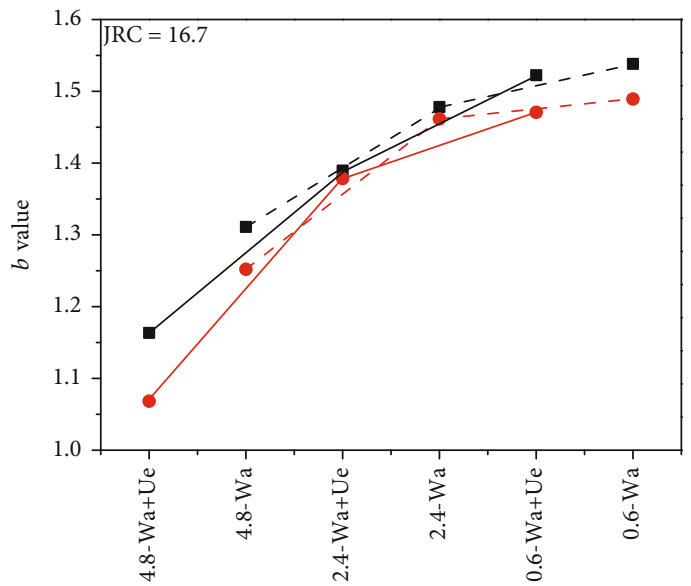

- Period-II

- Period-III

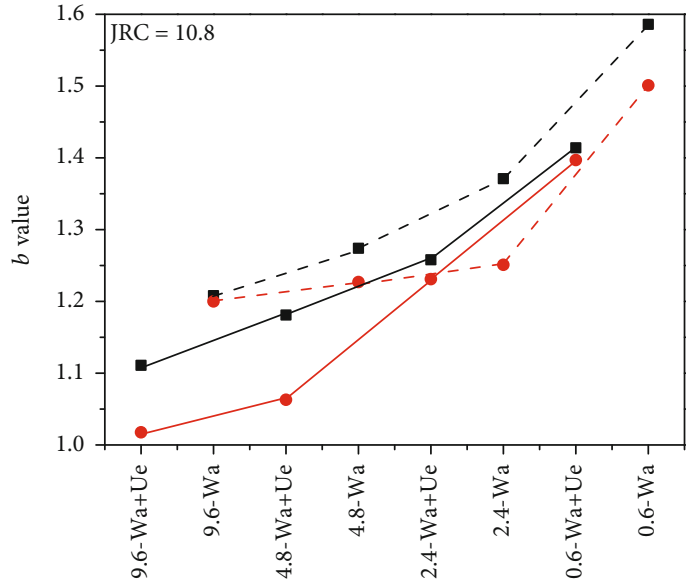

- Period-II

- Period-III

(b)

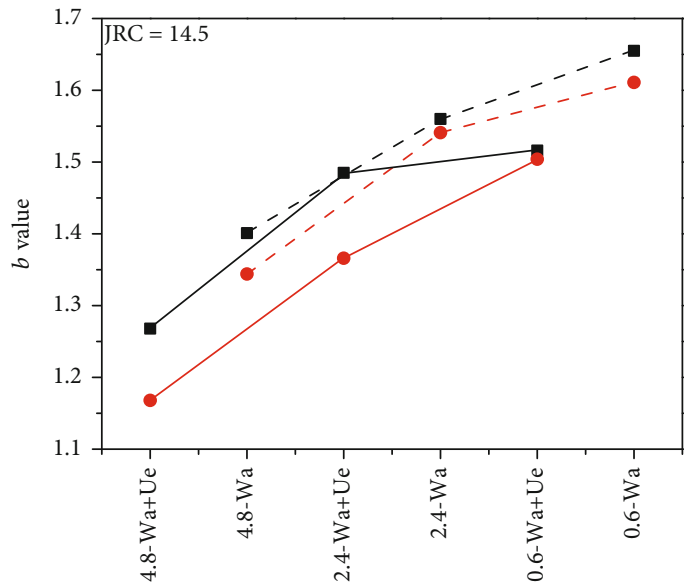

- Period-II

- Period-III

(d)

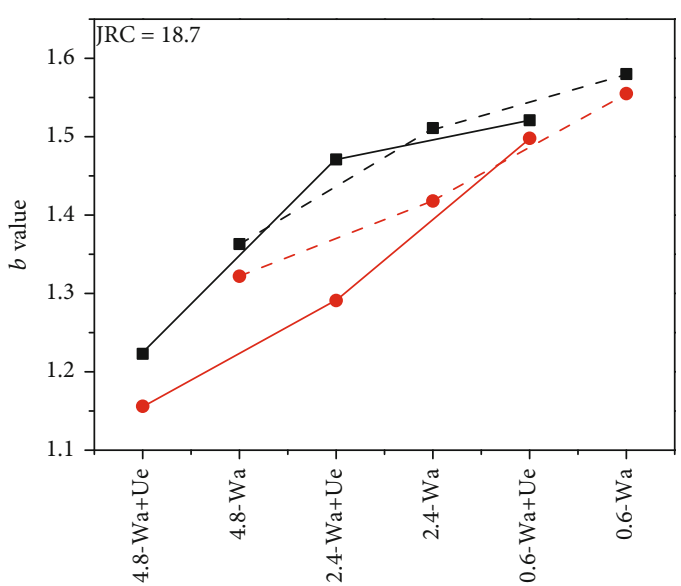

- Period-II

- Period-III

(e)

(f)

Figure 16: The AE- $b$ value. (a) JRC = 9.5. (b) JRC $=10.8$. (c) JRC $=12.8$. (d) JRC $=14.5$. (e) JRC $=16.7$. (f) JRC $=18.7$. 
where $A_{\mathrm{dB}}$ is the peak amplitude of the $\mathrm{AE}$ hits in $\mathrm{dB}$, $A_{\mathrm{dB}}=10 \log A_{\max }^{2}=20 \log A_{\max }, A_{\max }$ is the peak amplitude of the AE events in $\mu \mathrm{v}$, and $N$ is the number of acoustic emission events whose amplitude is greater than or equal to $A_{\mathrm{dB}}$.

The $b$ value is used to analyse the damage that occurs in the second and third shear stages of the joint specimen, and the analysis result is shown in Figure 16.

It can be seen from Figure 16, under the condition of the same morphology, the AE- $b$ value of joint specimen at the second period was greater than that at the third period, which means that the damage degree at the second period was less than that at the third period. For the same shearing period, as the normal stress increased, the value of $b$ gradually decreased, which means that the degree of joint damage increased with the increase of normal stress; besides, the $b$ value of the joint specimen containing the unevenness was smaller than that of the specimen only containing the waviness, indicating a greater damage degree.

\section{Conclusions}

In this research, the experimental investigation on the damage of the joint specimen with different asperity order was carried out to better understand the effect of asperity order on the mechanical properties. The standard roughness profile was used as the initial surface morphology, and the method combining the EEMD and cut-off level criterion was used to decompose the standard roughness profile into waviness and unevenness; two types of joint specimens, respectively, containing unevenness and only containing waviness were prepared using 3D engraving technologies and were subjected to shear tests under different normal stresses. The following conclusions can be drawn.

Under low normal stress, unevenness plays a key role in the failure mode. The joint specimen containing unevenness mainly suffered from shear failure, and the shear stress-shear displacement curve can be divided into $3 \mathrm{sec}-$ tions: climbing zone, gnaw zone, and slip zone; while the joint specimen only containing waviness suffered from sliding wear damage, and the shear stress-shear displacement curve can be divided into 2 sections: climbing zone and slip zone. When the normal stress is larger, the failure model of the joint specimen only containing waviness changes from sliding wear to shear failure.

Under low normal stress, unevenness plays a key role in the damaged area and damage volume. The damaged area, volume, and $\mathrm{AE}$ energy of the joint specimen containing the unevenness are larger than the specimen containing only the waviness. And the difference between them increases with the increase of normal stress.

Under low normal stress, the mechanical character difference between the joint specimen containing unevenness and only containing waviness mainly existed in the prepeak nonlinear stage and the postpeak stage. The AE energy of the joint specimen containing the unevenness is larger than that of the joint specimen only containing waviness.

The AE- $b$ value can be used to characterize the damage degree. The smaller the $b$ value, the greater the damage degree. The AE- $b$ value of the joint specimen containing the unevenness is smaller than that of the specimen only containing the waviness; the AE- $b$ value of the joint specimen at the postpeak stage is smaller than that of the joint specimen at the prepeak nonlinear stage.

\section{Data Availability}

All data and code generated or used during the study appear in the submitted article.

\section{Conflicts of Interest}

The authors declare that there is no conflict of interest regarding the publication of this paper.

\section{Acknowledgments}

This work was supported by (1) the scientific research project funded by the Department of Education of Hubei Province (Grant No. Q20201109), (2) Natural Science Foundation of Hubei Province (Grant No. 2020CFB123), and (3) Hubei Province Key Field R\&D Program Project (Grant No. 2020BCA082).

\section{Supplementary Materials}

Appendix 1: damaged area. Appendix 2: AE energy. Appendix 3: Matlab code for calculating the damage volume of the joint surface after shear test. (Supplementary Materials)

\section{References}

[1] S. Huang, Z. Lu, Z. Ye, and Z. Xin, "An elastoplastic model of frost deformation for the porous rock under freeze-thaw," Engineering Geology, vol. 278, article 105820, 2020.

[2] C. Wang, Y. Jiang, R. Liu, C. Wang, Z. Zhang, and S. Sugimoto, "Experimental study of the nonlinear flow characteristics of fluid in 3D rough-walled fractures during shear process," Rock Mechanics and Rock Engineering, vol. 53, no. 6, pp. 2581-2604, 2020.

[3] R. Liu, N. Huang, Y. Jiang, H. Jing, and L. Yu, "A numerical study of shear-induced evolutions of geometric and hydraulic properties of self-affine rough-walled rock fractures," International Journal of Rock Mechanics and Mining Sciences, vol. 127, article 104211, 2020.

[4] G. Han, H. Jing, Y. Jiang, R. Liu, and J. Wu, "Effect of cyclic loading on the shear behaviours of both unfilled and infilled rough rock joints under constant normal stiffness conditions," Rock Mechanics and Rock Engineering, vol. 53, no. 1, pp. 3157, 2020.

[5] Z. Tao, Y. Shu, X. Yang, Y. Peng, Q. Chen, and H. Zhang, "Physical model test study on shear strength characteristics of slope sliding surface in Nanfen open-pit mine," International Journal of Mining Science and Technology, vol. 30, no. 3, pp. 421-429, 2020.

[6] Z. C. Tang, Z. F. Zhang, and Y. Y. Jiao, “Three-dimensional criterion for predicting peak shear strength of matched discontinuities with different joint wall strengths," Rock Mechanics and Rock Engineering, vol. 54, no. 6, pp. 3291-3307, 2021. 
[7] Y. Zhao, C. Zhang, Y. Wang, and H. Lin, "Shear-related roughness classification and strength model of natural rock joint based on fuzzy comprehensive evaluation," International Journal of Rock Mechanics and Mining Sciences, vol. 137, article 104550, 2021.

[8] L. Ban, W. Du, T. Jin, C. Qi, and X. Li, “A roughness parameter considering joint material properties and peak shear strength model for rock joints," International Journal of Mining Science and Technology, vol. 31, no. 3, pp. 413-420, 2021.

[9] ISRM, "International Society for Rock Mechanics Commission on Standardization of Laboratory and Field Tests: suggested methods for the quantitative description of discontinuities in rock masses," International Journal of Rock Mechanics and Mining Sciences and Geomechanics Abstracts, vol. 6, no. 15, pp. 319-368, 1978.

[10] F. D. Patton, "Multiple models of shear failure in rock," in Proceedings of the First Congress of ISRM, Lisbon, 1966.

[11] N. Barton, "Review of a new shear-strength criterion for rock joints," Engineering Geology, vol. 7, no. 4, pp. 287-332, 1973.

[12] L. Jing, E. Nordlund, and O. Stephansson, "An experimental study on the anisotropy and stress-dependency of the strength and deformability of rock joints," International Journal of Rock Mechanics and Mining Sciences \& Geomechanics Abstracts, vol. 29, no. 6, pp. 535-542, 1992.

[13] D. D. Kana, D. J. Fox, and S. M. Hsiung, "Interlock/friction model for dynamic shear response in natural jointed rock," International Journal of Rock Mechanics and Mining Sciences \& Geomechanics Abstracts, vol. 33, no. 4, pp. 371-386, 1996.

[14] H. S. Lee, Y. J. Park, T. F. Cho, and K. H. You, "Influence of asperity degradation on the mechanical behavior of rough rock joints under cyclic shear loading," International Journal of Rock Mechanics and Mining Sciences, vol. 38, no. 7, pp. 967980, 2001.

[15] X. M. Zhu, H. B. Li, and B. Liu, "Experimental study of shear strength of joints with first-order and second-order asperities," Chinese Journal of Rock Mechanics and Engineering, vol. 30, no. 9, pp. 1810-1818, 2011.

[16] Z. Nie, X. Wang, D. L. Huang, and L. H. Zhao, "Fourier-shapebased reconstruction of rock joint profile with realistic unevenness and waviness features," Journal of Central South University, vol. 26, no. 11, pp. 3103-3113, 2019.

[17] Z. Y. Yang, C. C. Di, and K. C. Yen, "The effect of asperity order on the roughness of rock joints," International Journal of Rock Mechanics and Mining Sciences, vol. 38, no. 5, pp. 745-752, 2001.

[18] Z. Y. Yang, A. Taghichian, and W. C. Li, "Effect of asperity order on the shear response of three-dimensional joints by focusing on damage area," International Journal of Rock Mechanics and Mining Sciences, vol. 47, no. 6, pp. 10121026, 2010.

[19] Z. Jiang, P. Cao, X. Fan, Y. He, and W. Fan, "Evolution of joint morphology subjected to shear loads based on Gaussion filtering method," Journal of Central South University (Science and Technology), vol. 45, no. 6, pp. 1975-1982, 2014.

[20] X. G. Liu, W. C. Zhu, Q. L. Yu, S. J. Chen, and R. F. Li, "Estimation of the joint roughness coefficient of rock joints by consideration of two-order asperity and its application in double-joint shear tests," Engineering Geology, vol. 220, pp. 243-255, 2017.

[21] X. Liu, W. Zhu, Y. Liu, Q. Yu, and K. Guan, "Characterization of rock joint roughness from the classified and weighted uphill projection parameters," International Journal of Geomechanics, vol. 21, no. 5, article 04021052, 2021.

[22] M. Sharifzadeh, S. A. Mehri, and Y. Mirzaeian, "Multi-scale joints roughness characterization using wavelet and shear modeling," in ISRM Regional Symposium-7th Asian Rock Mechanics Symposium, Seoul, Korea, October 2012.

[23] L. C. Zou, L. R. Jing, and V. Cvetkovic, "Roughness decomposition and nonlinear fluid flow in a single rock fracture," International Journal of Rock Mechanics \& Mining Sciences, vol. 75, pp. 102-118, 2015.

[24] M. Wang, Y. F. Chen, G. W. Ma, J. Q. Zhou, and C. B. Zhou, "Influence of surface roughness on nonlinear flow behaviors in 3D self-affine rough fractures: lattice Boltzmann simulations," Advances in Water Resources, vol. 96, pp. 373-388, 2016.

[25] Y. Gui, C. Xia, W. Ding, X. Qian, and S. Du, "Modelling shear behaviour of joint based on joint surface degradation during shearing," Rock Mechanics and Rock Engineering, vol. 52, no. 1, pp. 107-131, 2019.

[26] Y. Li, S. Sun, and C. Tang, "Analytical prediction of the shear behaviour of rock joints with quantified waviness and unevenness through wavelet analysis," Rock Mechanics and Rock Engineering, vol. 52, no. 10, pp. 3645-3657, 2019.

[27] E. S. Hong, I. M. Lee, G. C. Cho, and S. W. Lee, "New approach to quantifying rock joint roughness based on roughness mobilization characteristics," KSCE Journal of Civil Engineering, vol. 18, no. 4, pp. 984-991, 2014.

[28] E. S. Hong, T. H. Kwon, K. I. Song, and G. C. Cho, "Observation of the degradation characteristics and scale of unevenness on three-dimensional artificial rock joint surfaces subjected to shear," Rock Mechanics and Rock Engineering, vol. 49, no. 1, pp. 3-17, 2016.

[29] F. Meng, L. N. Y. Wong, H. Zhou, Z. Wang, and L. Zhang, "Asperity degradation characteristics of soft rock-like fractures under shearing based on acoustic emission monitoring," Engineering Geology, vol. 266, article 105392, 2020.

[30] Y. Zong, L. Han, Q. Meng, and Y. Wang, "Strength properties and evolution laws of cracked sandstone samples in re-loading tests," International Journal of Mining Science and Technology, vol. 30, no. 2, pp. 251-258, 2020.

[31] H. Ran, Y. Guo, G. Feng, T. Qi, and X. Du, "Creep properties and resistivity-ultrasonic-AE responses of cemented gangue backfill column under high-stress area," International Journal of Mining Science and Technology, vol. 31, no. 3, pp. 401-412, 2021.

[32] X. P. Zhou and Y. X. Zhang, "Study on the property of acoustic emission straight shearing test of rock joint in Dachang Tongkeng mine," Chinese Journal of Rock Mechanics and Engineering, vol. 21, no. 5, pp. 724-727, 2002.

[33] Z. A. Moradian, G. Ballivy, P. Rivard, C. Gravel, and B. Rousseau, "Evaluating damage during shear tests of rock joints using acoustic emissions," International Journal of Rock Mechanics \& Mining Sciences, vol. 47, no. 4, pp. 590-598, 2010.

[34] F. Z. Meng, H. Zhou, Z. Q. Wang et al., "Characteristics of asperity damage and its influence on the shear behavior of granite joints," Rock Mechanics and Rock Engineering, vol. 51, no. 2, pp. 429-449, 2018.

[35] Y. Chen and Z. Zhao, "Correlation between shear induced asperity degradation and acoustic emission energy in single granite fracture," Engineering Fracture Mechanics, vol. 235, article 107184, 2020. 
[36] R. Yong, J. Ye, Q. F. Liang, M. Huang, and S. G. Du, "Estimation of the joint roughness coefficient (JRC) of rock joints by vector similarity measures," Bulletin of Engineering Geology \& the Environment, vol. 47, no. 10, pp. 1-15, 2018.

[37] C. Pickering and A. Aydin, "Modeling roughness of rock discontinuity surfaces: a signal analysis approach," Rock Mechanics and Rock Engineering, vol. 49, no. 7, pp. 29592965, 2016.

[38] Z. Wu and N. E. Huang, "Ensemble empirical mode decomposition: a noise-assisted data analysis method," Advances in Adaptive Data Analysis, vol. 1, no. 1, pp. 1-41, 2009.

[39] N. E. Huang, Z. Shen, S. R. Long et al., "The empirical mode decomposition and the Hilbert spectrum for nonlinear and non-stationary time series analysis," Proceedings of the Royal Society, vol. 454, no. 1971, pp. 903-995, 1998.

[40] C. C. Xia, "The waviness characteristics and mechanical effects of topography of rock structure faces," Journal of Tongji University, vol. 21, no. 3, pp. 371-377, 1993.

[41] J. Lu, "Polarization spectrum sensing exploiting eigenvalue based goodness-of-fit detection," in 2020 IEEE 5th International Conference on Signal and Image Processing (ICSIP), pp. 955-959, Nanjing, China, October 2020.

[42] Q. Jiang, B. Yang, F. Yan, C. Liu, Y. Shi, and L. Li, "New method for characterizing the shear damage of natural rock joint based on 3D engraving and 3D scanning," International Journal of Geomechanics, vol. 20, no. 2, pp. 1-15, 2020.

[43] H. Zhou, G. T. Cheng, Y. Zhu et al., "Study on anisotropy of shear characteristics of rock joint based on 3D carving technique," Rock and Soil Mechanics, vol. 40, no. 1, pp. 118-126, 2019.

[44] Q. Z. Zhang, M. R. Shen, and W. Q. Ding, "Study on the mechanical properties of rock mass discontinuity under shear condition," Hydrogeology \& Engineering Geology, vol. 39, no. 2, pp. 42-47, 2012.

[45] P. H. S. W. Kulatilake, G. Shou, T. H. Huang, and R. M. Morgan, "New peak shear strength criteria for anisotropic rock joints," International Journal of Rock Mechanics and Mining Sciences and Geomechanics Absatracts, vol. 32, no. 7, pp. 673-697, 1995.

[46] Q. Jiang, L. B. Song, F. Yan, C. Liu, B. Yang, and J. Xiong, "Experimental investigation of anisotropic wear damage for natural joints under direct shearing test," International Journal of Geomechanics, vol. 20, no. 4, article 04020015, 2020.

[47] S. K. Singh, S. Raval, and B. P. Banerjee, “A robust approach to identify roof bolts in $3 \mathrm{D}$ point cloud data captured from a mobile laser scanner," International Journal of Mining Science and Technology, vol. 31, no. 2, pp. 303-312, 2021.

[48] B. Indraratna, S. Thirukumaran, E. T. Brown, W. Premadasa, and W. Gale, "A technique for three-dimensional characterisation of asperity deformation on the surface of sheared rock joints," International Journal of Rock Mechanics and Mining Sciences, vol. 70, pp. 483-495, 2014.

[49] Y. Gui, C. Xia, W. Ding, X. Qian, and S. Du, "A new method for $3 \mathrm{D}$ modeling of joint surface degradation and void space evolution under normal and shear loads," Rock Mechanics \& Rock Engineering, vol. 50, no. 10, pp. 28272836, 2017.
[50] G. Grasselli, J. Wirth, and P. Egger, "Quantitative threedimensional description of a rough surface and parameter evolution with shearing," International Journal of Rock Mechanics and Mining Sciences, vol. 39, no. 6, pp. 789-800, 2002.

[51] X. Lei, "Evolution of $b$-value and fractal dimension of acoustic emission events during shear rupture of an immature fault in granite," Applied Sciences, vol. 9, no. 12, article 2498, 2019. 